\title{
TV/Series
}

19 | 2021

Perfectionnisme et séries télévisées. Hommage à Stanley Cavell (1926-2018)

\section{Bons voisinages dans Show me a hero}

\section{Sophie Wahnich}

\section{(2) OpenEdition}

Journals

Édition électronique

URL : https://journals.openedition.org/tvseries/5168

DOI : 10.4000/tvseries.5168

ISSN : 2266-0909

Éditeur

GRIC - Groupe de recherche Identités et Cultures

\section{Référence électronique}

Sophie Wahnich, "Bons voisinages dans Show me a hero », TV/Series [En ligne], 19 | 2021, mis en ligne le 06 mai 2021, consulté le 14 mai 2021. URL : http://journals.openedition.org/tvseries/5168 ; DOI :

https://doi.org/10.4000/tvseries.5168

Ce document a été généré automatiquement le 14 mai 2021.

\section{(c)}

TV/Series est mis à disposition selon les termes de la licence Creative Commons Attribution - Pas d'Utilisation Commerciale - Pas de Modification 4.0 International. 


\title{
Bons voisinages dans Show me a hero
}

\author{
Sophie Wahnich
}

\section{Introduction : « Neighbourhood»}

1 En anglais le mot voisin se dit «neighbour», et aux États-Unis, on habite moins un quartier « block » ou « district » qu'un « neighbourhood». On habite donc littéralement un «voisinage », et c'est en fonction de ce voisinage plus ou moins «bon » que l'on va considérer qu'un quartier est résidentiel ou non, en fait fréquentable ou non, suffisamment protégé de la violence urbaine ou non.

2 "Princeton is the only good neighbourhood, in New Jersey", m'a dit un jour un chauffeur de taxi fraichement arrivé aux États-Unis et venant du Brésil. Cela voulait dire que Princeton est la seule ville blanche et riche selon lui du New Jersey. Sa voisine Trenton, elle, est noire. Réputée pour ses shootings intracommunautaires, on vous conseille de ne faire que passer si vous avez besoin de changer de train dans ce nœud ferroviaire. Le Brésil comme les États-Unis sont des terres de ségrégation. Cette ségrégation n'appartient pas au passé, elle détermine l'organisation sociale, raciale et spatiale de l'habitat américain, en fait de la société américaine.

3 La mini-série Show Me a Hero, est un produit HBO, créée par David Simon et réalisée par Paul Haggis, diffusée initialement en août 2015. David Simon, est un peu un spécialiste, si l'on peut dire, des dégâts produits par cette ségrégation. Il les a observés et mis en scène dans The Wire à Baltimore. Or la critique avait alors porté sur sa vision désespérante des pathologies sociales ${ }^{1}$, comme si rien n'était jamais réformable dans les villes ou quartiers pauvres. Ici le scénariste et le réalisateur prennent le parti pris inverse. Ils questionnent comment les victimes peuvent se ressaisir de leur vie, se politiser, ou simplement se " perfectionner $»^{2}$.

4 La ségrégation est mise en scène ici à Yonkers, ville du nord de l'État de New York, voisine en quelque sorte de New York City. Car un État comme celui de New York avec sa ville légendaire, elle-même faite de quartiers peu mixés, si l'on y regarde de près, est emblématique des écarts sociaux et spatiaux américains. Le regard porté sur le voisinage se fait donc sur plusieurs échelles et plusieurs représentations, y compris la 
représentation d'un voisinage temporel entre un passé proche, celui des années 1980 qui sont celles de l'intrigue, notre présent qui motive la réalisation de cette mini-série car, David Simon l'explique clairement dans toutes les émissions de radio et de télé ${ }^{3}$ qu'il a acceptées de faire autour, il parle d'aujourd'hui en utilisant cette histoire tragique d'hier, car il s'agit de raconter en fait une tragédie, mais aussi de saisir au présent les traces d'un passé tragique plus lointain.

5 La tragédie des années 1980 est celle d'un jeune maire de Yonkers, inexpérimenté et venant d'un milieu modeste. Il a été poussé en position de candidat dans une configuration que l'on pensait perdue d'avance. Mais il gagne. Fraichement élu, il met en œuvre une politique de déségrégation imposée par le pouvoir fédéral et plus précisément la cour suprême, qui défendent ainsi les droits civils états-uniens. Mais il avait promis à son électorat de refaire appel contre cette décision. Ayant compris que la loi ne pourrait pas être contournée, il décide courageusement de faire le bon soldat du droit fédéral, seul rempart contre la ségrégation effective. Il est alors violement attaqué par ses adversaires politiques et par la collectivité blanche raciste de Yonkers, il y perd sa popularité mais fait construire les logements sociaux. Il est alors négligé par son propre parti politique qui lui préfère un candidat plus conforme à l'élite démocrate américaine. Un candidat plus éduqué, plus riche, plus carriériste, plus retord. Oublié de la population au moment où le projet de logement prend corps, il ne supporte pas sa marginalisation et finit par se suicider. Mais cette tragédie en masque une autre, celle de cette fameuse ségrégation qui fonctionne comme une "nappe immobile de temps " ${ }^{4}$. Un temps « enkysté d'oubli » nous dit Nicole Loraux, un temps entre les temps, temps de passion, au sens où la passion s'oppose à l'action. Cette nappe recouvre ce qui semble impossible à déplacer, lieu du déni.

6 Les dégâts d'une longue ségrégation sont des dégâts de longue durée, plus l'expérience s'ancre dans les mœurs quotidiennes et plus il est difficile de pouvoir en décoller. On retrouve alors le Pierre Bourdieu du Sens pratique où l'habitus permet de penser la reconduction du passé dans le présent, dans des formes d'agir inconscientes pour des individus d'un groupe. « Histoire incorporée, faite nature, et par là oubliée en tant que telle, l'habitus est la présence agissante de tout le passé dont il est le produit ${ }^{5}$.

7 Impossible d'imaginer pouvoir vivre bien aux côtés des noirs pour les blancs qui manifestent contre l'implantation de nouveaux logements dans leur «voisinage». Difficile d'avoir envie même d'habiter avec des blancs pour les noirs qui n'en peuvent plus du mépris ou du paternalisme condescendant qu'ils ont toujours subi. Cela est explicitement dit dans la série. Un des personnages, infirmière noire qui a perdu la vue, et dont les enfants prennent grand soin, n'a pas envie de quitter son « chez elle », qui n'est pas seulement sa maison mais bien son «neighbourhood", elle veut vivre avec des noirs quand ses enfants veulent qu'elle déménage dans un meilleur quartier où les aides ménagères n'auront plus peur d'aller. Après avoir déménagé, elle quittera le nouveau quartier pour aller en Virginie noire. Auparavant, sa fille aura voulu l'emmener au restaurant mais comprenant sans le voir, que le lieu choisi par son enfant est peuplé uniquement de blancs, elle ne souhaite pas rester. Sa fille est déçue et incarne l'espoir encore existant d'une déségrégation possible du côté noir dans une plus jeune génération. C'est en tout cas l'espoir de David Simon et Paul Haggis qui savent que cet espoir il faut le mettre en scène sans illusion, c'est-à-dire montrer aussi que ce n'est pas assuré et que les meilleures intentions ne peuvent suffire à se réconcilier avec une histoire américaine dévastatrice, à réparer un corps social dévasté. 
Ils mettent en scène la conversation de deux juristes favorables à cette déségrégation, l'un est noir et l'autre juif. Mais le noir explique au juif, qu'à force d'avoir vu les blancs refuser d'ouvrir leurs cœurs et leurs quartiers aux noirs, les noirs n'ont plus envie d'habiter avec des blancs. Tragédie d'une progression sociale qui ne peut se traduire en déségrégation spatiale et mentale. Tragédie aussi des juifs qui ont longtemps lutté aux côtés des noirs pour les droits civiques ${ }^{6}$ et sont perçus comme blancs par les noirs et comme juifs par les suprémacistes blancs.

Figure 1 : Conversation entre deux juristes, un juif et un noir (S01E01)

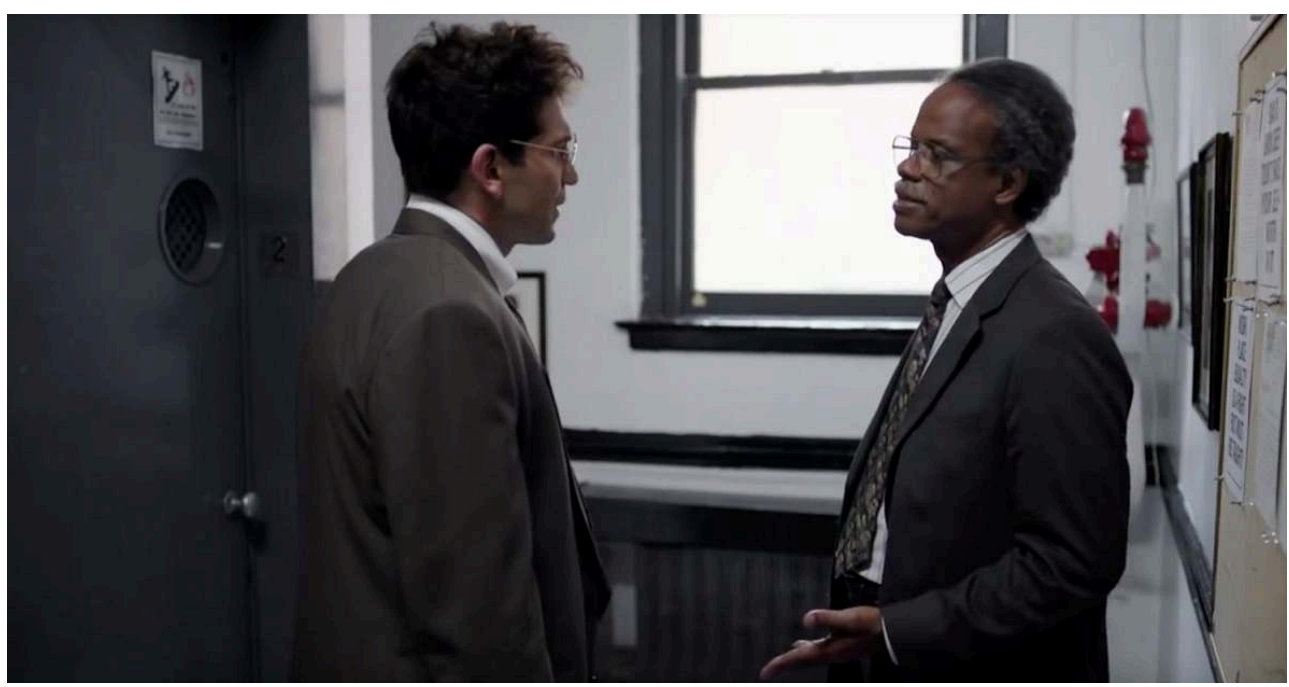

Cet avocat New yorkais, dont le nom de famille est « Sussman » est pendu en effigie par les manifestants blancs de Yonkers.

Figure 2 : L'effigie, le leader suprémaciste avec un porte-voix (S01E04)

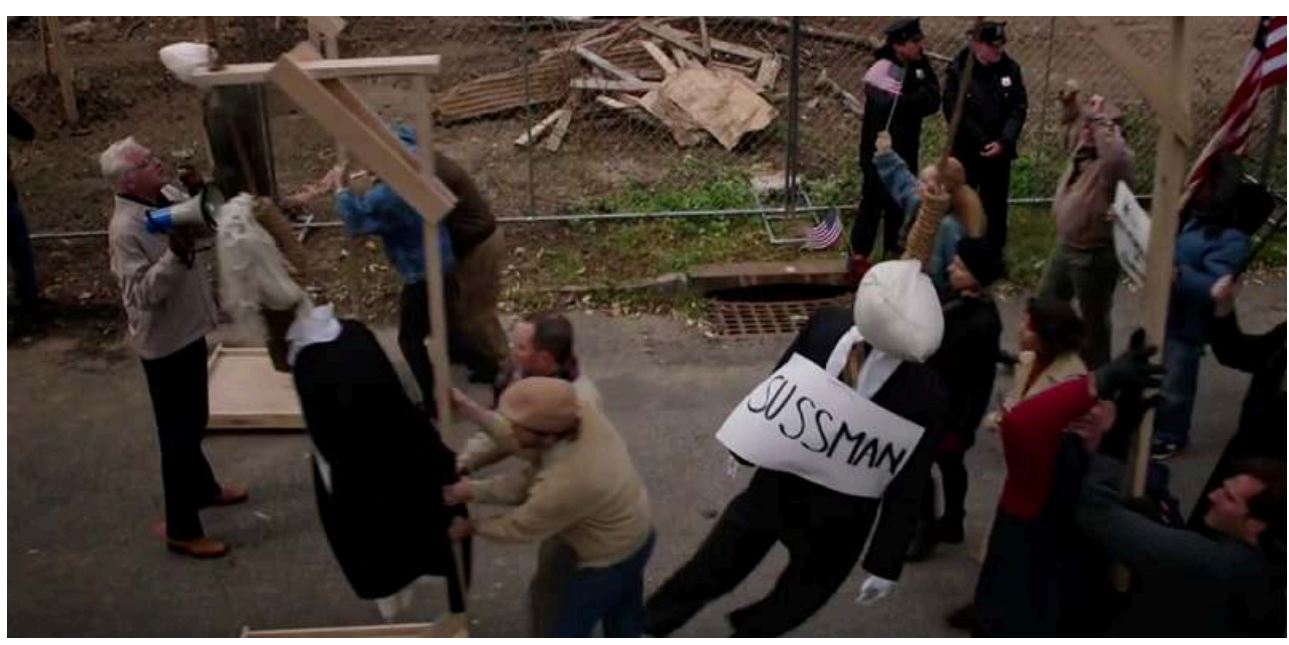

La mini-série est de 2015, les événements de Charlotteville de 2017. Alors les suprémacistes blancs ont crié « Juifs, vous ne nous remplacerez pas ». La fiction voisine ainsi doublement avec le réel, celui du passé et maintenant du futur.

10 Aussi faut-il bien reconnaitre que la nappe de temps immobile est une actrice de la vie politique américaine, et reconnaître aussi que les juifs occupent encore ou à nouveau sur la scène politique ordinaire américaine, la position impossible, trop blancs pour les 
uns et pas assez pour les autres, marquant l'échec d'une intégration véritablement réussie.

Figure 3 : Suprémacistes blancs à Charlotteville scandant " Jews, Jews you won't remplace US ", novembre 2017 (photo tirée de la version web du magazine Moment, « The New Old Hate Talk », by Ellen Wexler, November 1, 2017, https://momentmag.com/new-old-hate-talk/)

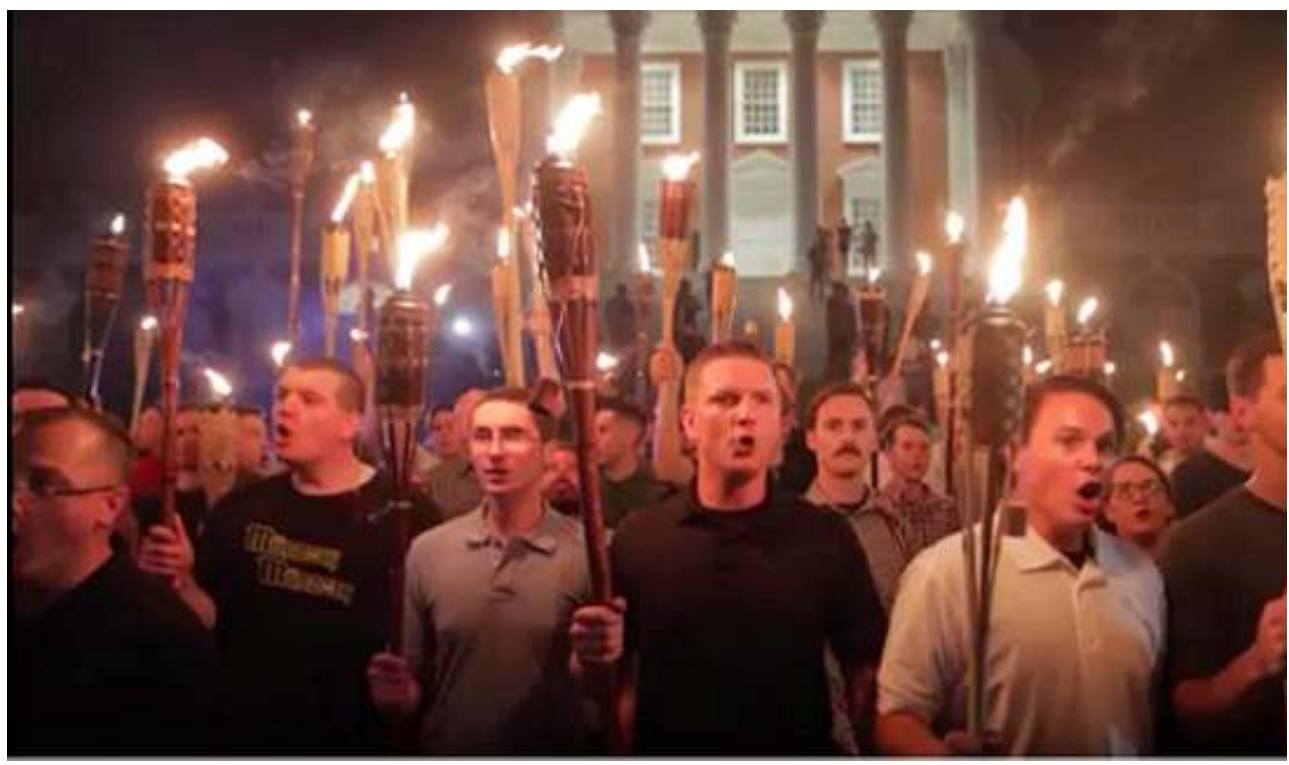

11 Les juifs américains, ou plutôt beaucoup d'entre eux, ont voulu être blancs, mais d'autres ont en mémoire une histoire proche symboliquement (sortir de la servitude) et historiquement (être en proie à la volonté d'extermination), et se souviennent des raisons d'une alliance avec la communauté noire pour les droits civiques. Ils luttent aujourd'hui pour l'accueil des migrants et des réfugiés. Leur idéal est universaliste et ils se retrouvent dans la ligne de mire des suprémacistes blancs, et cela au même titre que les noirs et les musulmans, sans que désormais il soit aisé de faire alliance, tant les communautés sont identitaires et clivées. La série montre que ce clivage identitaire de la société américaine la ronge.

12 Aujourd'hui la force d'inertie de la société américaine, c'est-à-dire tout ce que l'histoire a produit tant sur le plan matériel que sur le plan des idées de fondamentalement raciste, son "pratico-inerte» aurait dit Sartre ${ }^{7}$, semble plus fort que tous les efforts entrepris par une communauté d'habitants souhaitant s'en émanciper à Yonkers, souhaitant se perfectionner.

\section{Stanley Cavell, David Simon et Paul Haggis}

Stanley Cavell pour faire comprendre ce qu'il entendait par perfectionnisme, donnait une liste d'œuvres à ses étudiants plutôt qu'une définition. Pour ajouter une œuvre à cette liste et ainsi la compléter, il fallait pouvoir le justifier. La mini-série américaine Show Me a Hero peut-elle être ajoutée à cette liste?

Sur le plan des intentions, David Simon et Paul Haggis sont clairs, ils savent que c'est bien ce qu'ils mettent en scène très consciemment, l'espoir que le perfectionnisme américain $^{8}$ puisse venir à bout de cette nappe immobile du temps, de ses dégâts. Or dans cette mini-série les dégâts qui les intéressent en premier lieu ne sont pas ceux qui 
pèsent sur les populations ségrégées, mais ceux qui pèsent sur les blancs américains dont l'histoire et donc le pratico-inerte est ségrégationniste. Ce que dit la mini-série, c'est que la société américaine ne pourra se transformer que si cette population là déplace sa raison sensible cette capacité à produire un jugement articulé à des arguments et surtout à une expérience sensible ${ }^{9}$. C'est pourquoi ils s'intéressent avec intensité au personnage de Mary Dorman. C'est même sans doute le personnage central de cette série sur le plan du perfectionnisme individuel. Ce perfectionnisme qui conduit Emerson à affirmer dans «Fate» en 1851: "Cependant, pour moi, la question de l'époque s'est résolue en une question pratique : celle de la conduite de la vie. Comment dois-je vivre ? Nous sommes incompétents pour élucider [solve] les questions de l'époque. Notre géométrie ne suffit pas à couvrir les immenses orbites des idées dominantes, à observer leur retour ni à résoudre leurs oppositions. Nous ne pouvons obéir qu'à notre polarité. $»^{10}$ Or, si « Fate» en 1851 c'est l'esclavage, alors insoluble, «Fate » aujourd'hui reste cette ségrégation. Cependant Mary Dorman permet d'espérer vraiment en l'humanité et même le héros de l'histoire, Nick Wasicsko, n'occupe qu'une place latérale qui permet de mieux voir Mary. David Simon et Paul Haggis la suivent dans ses déambulations publiques et privées et suivent le caractère changeant de son visage, Il convient alors de penser au terme tel qu'Emmanuel Levinas en fait usage, il nomme visage, la vulnérabilité et la nudité d'un tout autre qui m'excède infiniment. Visage miroir des émotions qui traversent le sujet et lui donnent son humanité, dans son altérité comme dans sa proximité avec le spectateur. Visage miroir aussi de l'infinini ${ }^{11}$.

Manifestation d'un visage par-delà la forme. [...] Le visage est une présence vivante, il est expression. [...] Le visage parle. [...] Le discours n'est pas simplement une modification de l'intuition (ou de la pensée), mais une relation originelle avec l'être extérieur. [...] Il est production de sens. Le sens ne se produit pas comme une essence idéale - il est dit et enseigné par la présence ${ }^{12}[. .$.$] .$

15 Or cette présence est forte et profonde. Elle nous semblait à nous qui suivons la logique des producteurs, terrible dans sa manière d'hurler avec les loups blancs et elle devient la personne aimable entre toutes, dans sa capacité à avoir su observer, écouter, penser, décider, s'amender, et devenir la meilleure des voisines imaginable. C'est en fait l'incarnation du perfectionnisme individuel.

Mais de fait, cela ne suffit pas. Car, chez Ralph Waldo Emerson :

Un homme doit chevaucher alternativement sa nature privée et sa nature publique [...] Abandonnant le daïmon qui subit, il doit choisir le camp de la Déité qui par sa douleur assure un profit universel ${ }^{13}$.

17 Et c'est bien ce que fait le héros de Yonkers, et c'est donc bien à ce titre le protagoniste, mais il en meurt. Pour autant le travail politique qu'il a tenté aura été fécondant et c'est sans doute tout l'enjeu de cette série, le maire meurt alors qu'en fait il a réussi à contribuer au perfectionnement de cette ville, d'une partie de ses habitants, sans réussir à tenir sous le choc de son héroïsme et donc sans doute à se perfectionner suffisamment lui-même, pour laisser la place à la vie, plutôt qu'à la mort. Car « s'il existe un perfectionnisme qui non seulement est compatible avec la démocratie mais lui est nécessaire, il ne consiste pas à excuser les ratages inévitables de la démocratie ou à essayer de s'élever au-dessus de ces ratages, mais à enseigner à réagir à ces ratages et aux compromissions auxquelles ils nous mêlent, autrement que par l'excuse ou le recul ${ }^{14}$. ». Nick a d'abord accepté le fonctionnement de son parti, puis choisi d'adopter une position juste, de tenter d'être un bon maire, il l'explique à Mary Dorman. Il a été 
élu pour diriger et il essaye de le faire de son mieux en choisissant de faire ces logements. Puis, dans la difficulté, il se compromet à nouveau, met en danger le travail de sa femme et quand il prend du recul, il ne le supporte pas. Nick est un héros vacillant.

Le suicide de Nick peut d'abord être vu comme une question privée, mais déjà Émile Durkheim avait su montrer que certes, la dimension privée ne pouvait être négligée mais que c'était quand même tout autant une affaire sociale. Ce suicide de Nick, dont seule la femme a vraiment pris soin, est aussi l'expression publique et collective d'un problème d'abord vu comme privé ${ }^{15}$. Ce problème n'est pas seulement celui de Nick mais bien celui de la manière dont fonctionne la vie politique américaine, elle fabrique une "ontologie de l'insensibilité $»^{16}$, l'indifférence des acteurs à la violence qu'ils produisent, l'indifférence des populations qui ne voient les politiciens que comme des gens à part, sans doute privilégiés, et ne peuvent plus les considérer comme des êtres humains ordinaires, soumis à rude épreuve, drogués, fragiles et défaillants, méritant attention.

Mais sans doute cela ne suffit toujours pas, il s'agit aussi malgré tout, d'interroger les comportements du parti démocrate américain. Ce parti, dans lequel Nick n'a pas réussi à trouver une place satisfaisante, doit lui aussi devenir vraiment capable de perfectionnement, c'est-à-dire capable d'écoute des siens et des autres souffrant, redevenir soucieux de son humanité et de l'humanité. Il y faudrait plus d'attention des uns aux autres, plus de droiture, de vérité. Cette mini-série mérite d'être sur la liste de Stanley Cavell aussi au titre de cette inquiétude.

La véritable question n'est donc pas ou pas seulement de savoir si cette série questionne le perfectionnisme comme enjeu démocratique, mais au delà du scénario d'ensemble, comment elle réussit à nous rendre sensible à ces grandes questions du " fate » américain, à sa possible prise en charge individuelle et à sa nécessaire prise en charge collective. Quelles sont les joies, les aléas, les gestes et les défaillances ordinaires qui traversent les personnages et en font des fictions disponibles pour notre propre perfectionnement. Á quoi devenons-nous sensibles grâce à cette mini-série?

\section{Yonkers, État de New York}


Figure 4 : Yonkers apparaît à l'écran (S01E01)

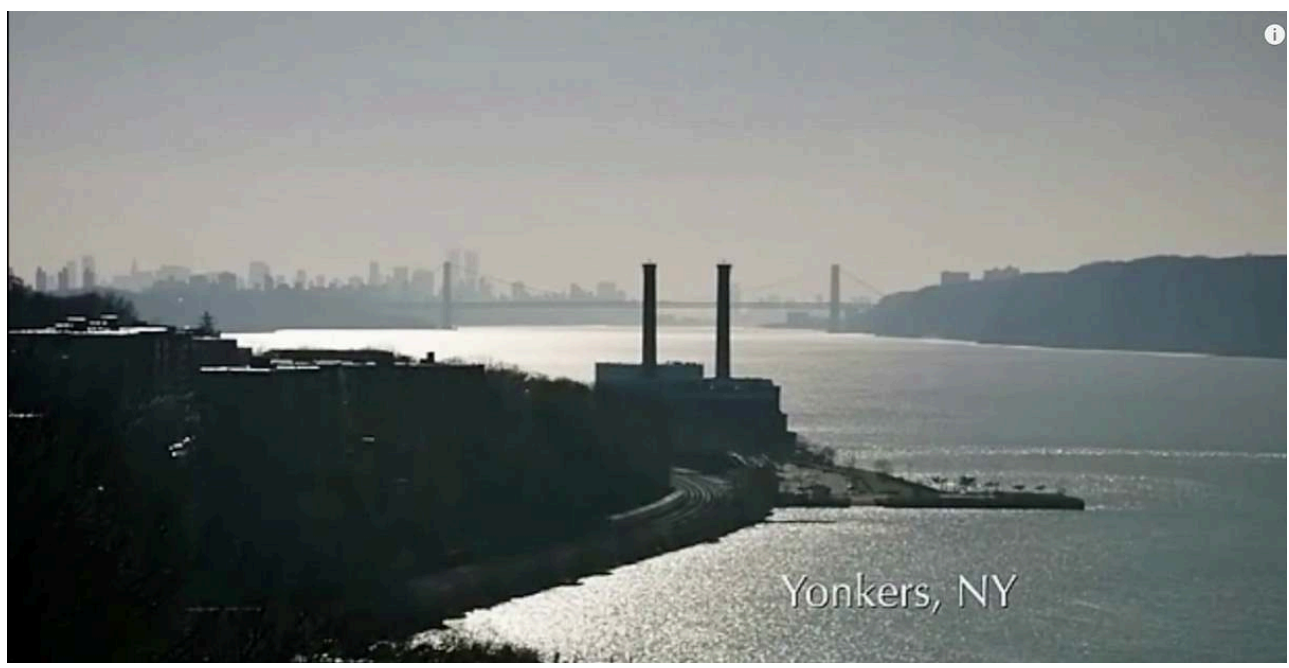

Lorsque Yonkers apparaît à l'écran dans une prise de vue d'ensemble, se dessine à l'horizon le skyline de New York City tandis que deux cheminées d'usine sont plantées au cœur du paysage. Tout est déjà là dans un conflit des désirs. La ville désirable c'est New York et le spectateur va pouvoir bientôt l'admirer, car un homme décolle d'un héliport et survole la ville fantasmatique avant d'arriver dans ce moyen de transport luxueux au dessus de Yonkers. Pendant son trajet, on aura vu un train circuler au sol, le moyen de transport ordinaire des gens qui n'ont pas de voitures. Le train est aussi un lieu ségrégé aux États-Unis où seules les grandes lignes Amtrak aussi chères que l'avion sont fréquentées par tous. Les lignes régionales le sont par des gens très modestes, ils sont noirs, latinos ou fraichement arrivés aux États-Unis, ne parlent pas toujours anglais entre eux. En un clin d'œil, une prise de vue, la question sociale est convoquée.

Figure 5 : New York City (S01E01)

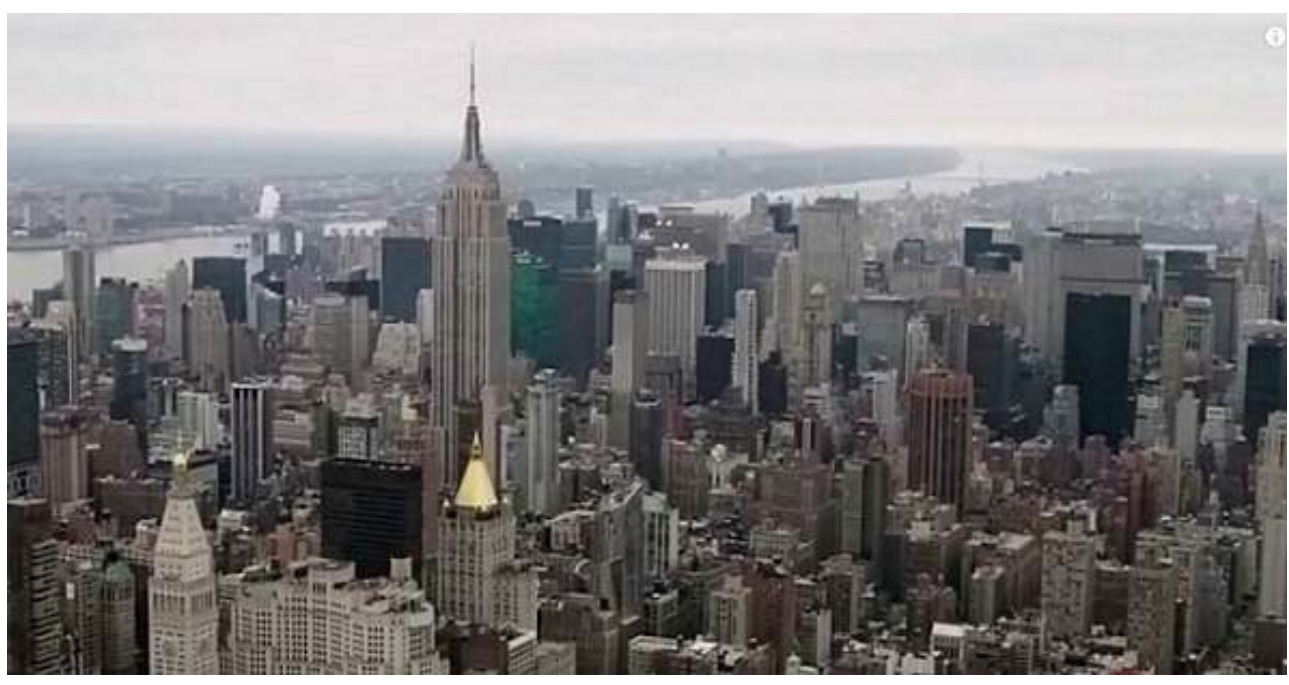

La traversée des différents quartiers de la ville en voiture permet de rentrer dans le vif du sujet de Yonkers. Quartiers middle-class où de nombreux drapeaux américains plantés dans la façade, témoignent du patriotisme. 
Figure 6 : Patriotisme (S01E01)

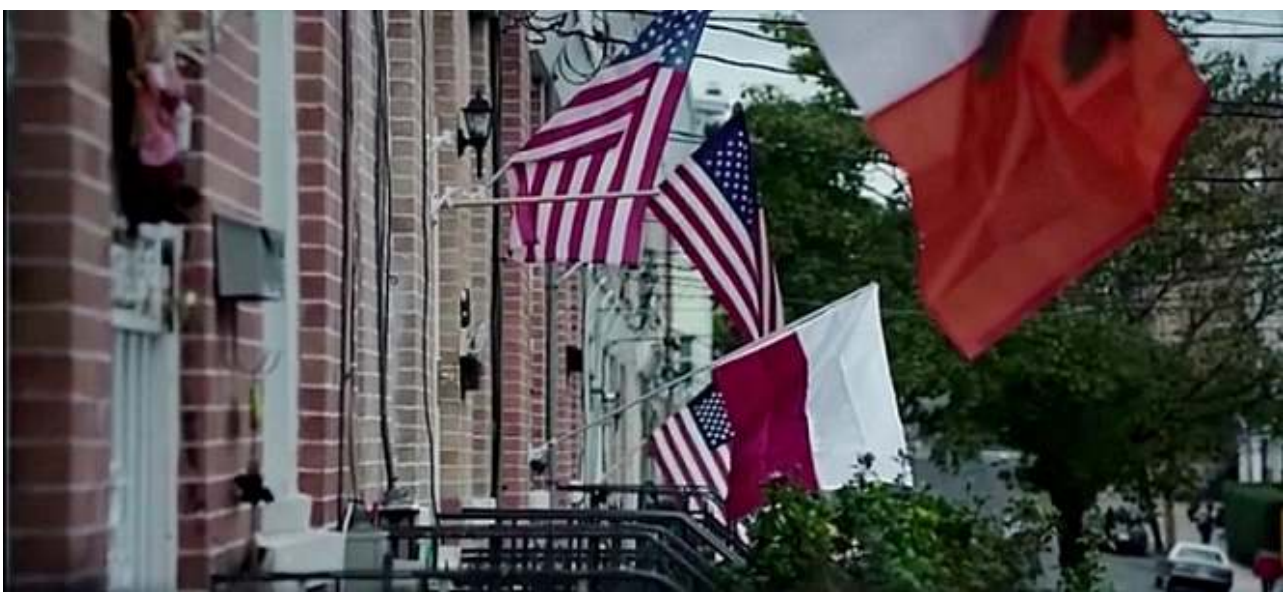

Figure 7 : Maisons classiques (S01E01)

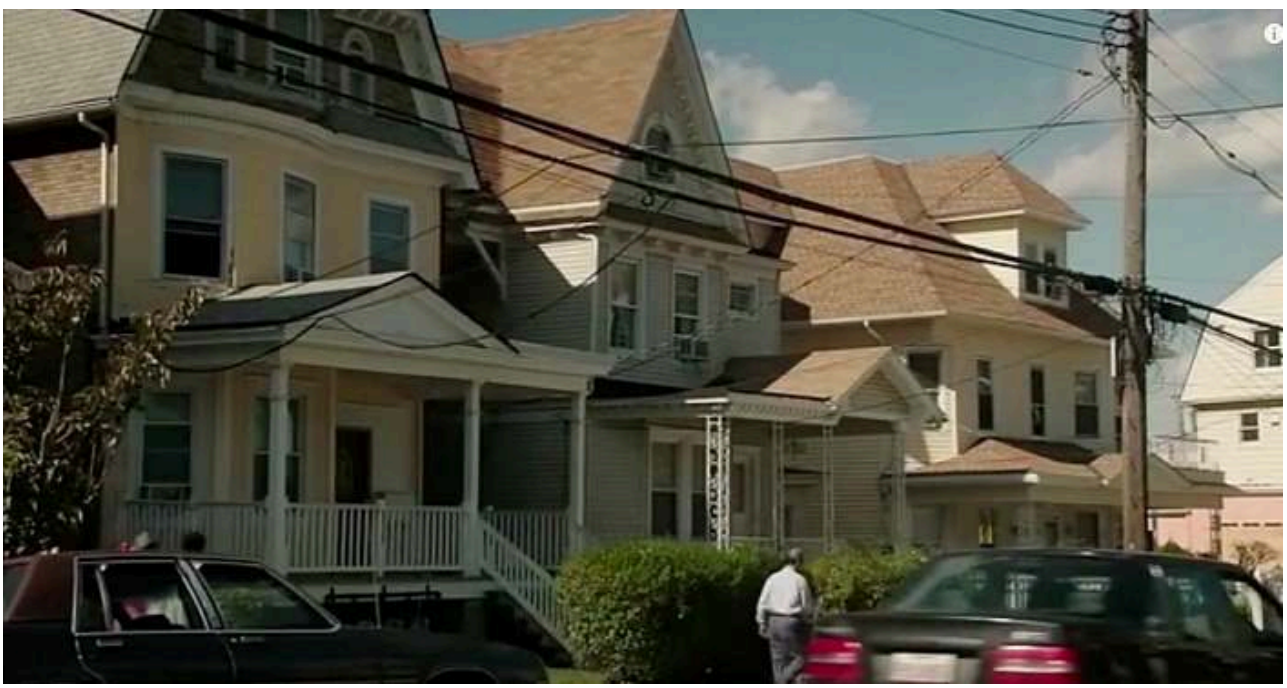

Figure 8 : Maison délabrée (S01E01)

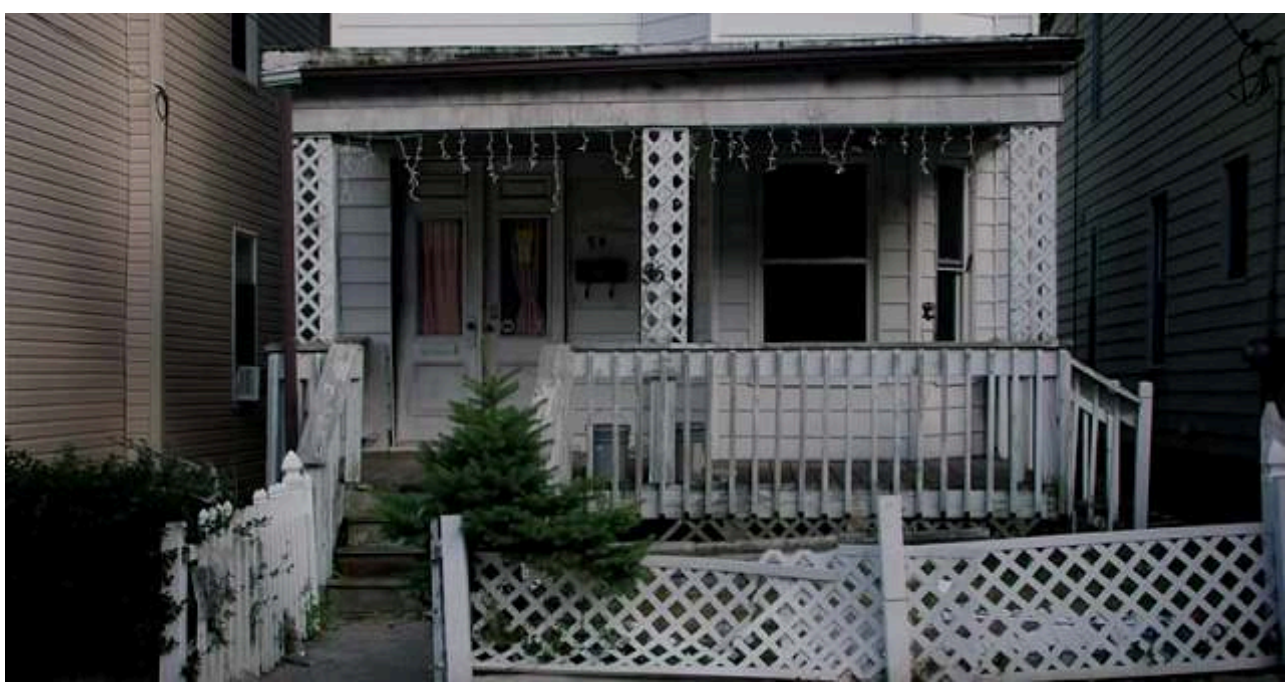


23 uartiers plus neutres de maisons de bois, maisons fragiles qui ne supportent pas longtemps d'être inhabitées, l'une d'elle où sont encore installées des décorations de Noël apparaît à l'écran dans son délabrement. Et puis il y a les beaux quartiers où l'on construit en dur une « mansion » avec un grand jardin autour.

Figure 9 : Quartier chic (S01E01)

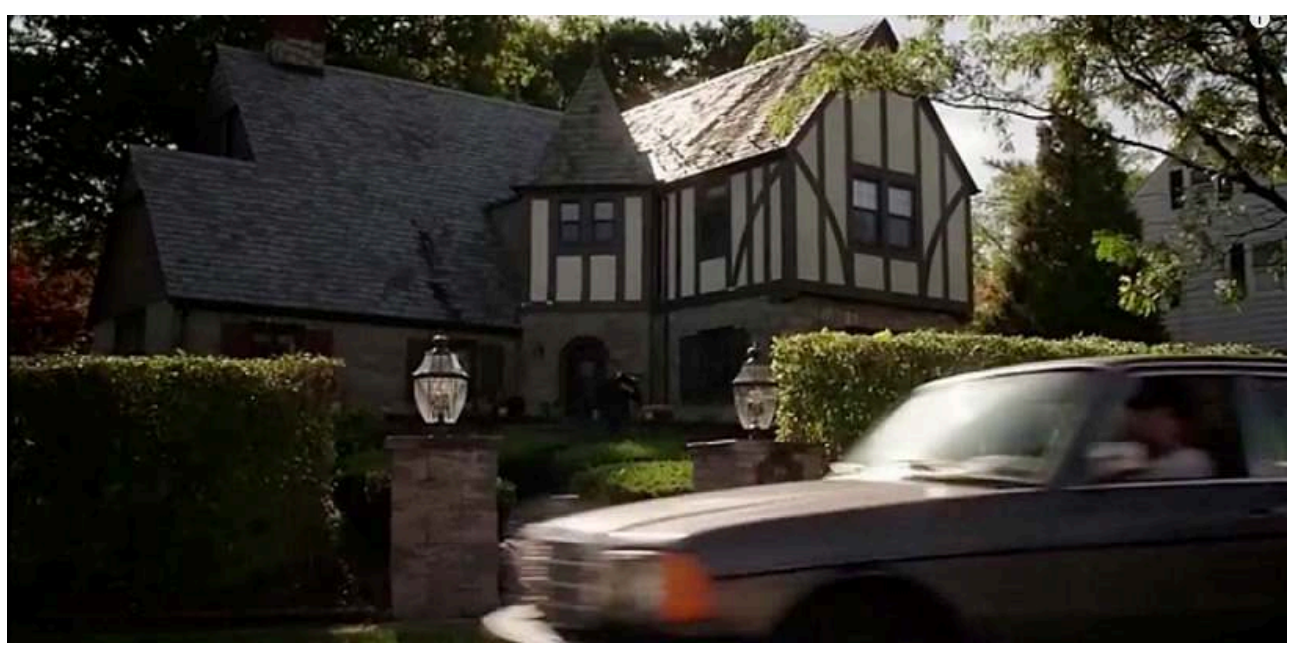

Enfin, à l'autre bout de l'échelle sociale il y a la cité : Schlobohm. C'est délabré et taggué, des meubles abandonnés servent de salon à ciel ouvert. La population est majoritairement noire, elle était blanche ailleurs. La police est devenue omniprésente.

Figures 10, 11 et 12 : S'approcher de Schlobohm (S01E01)

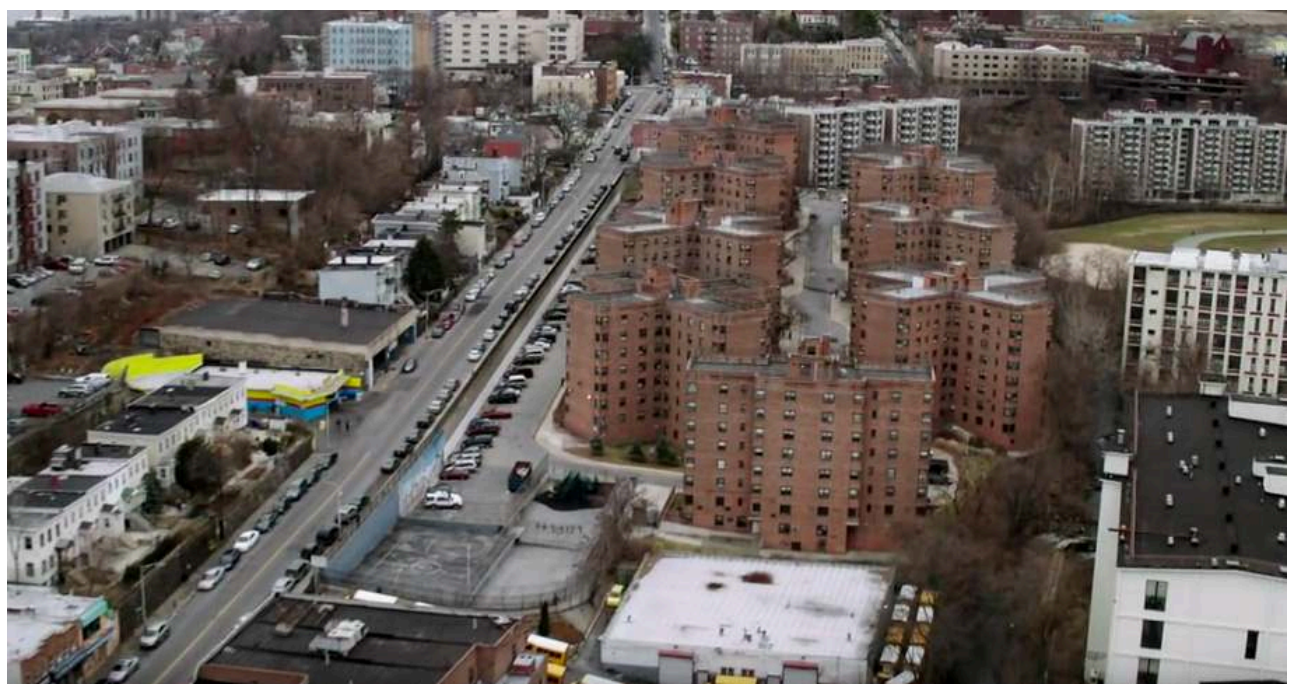



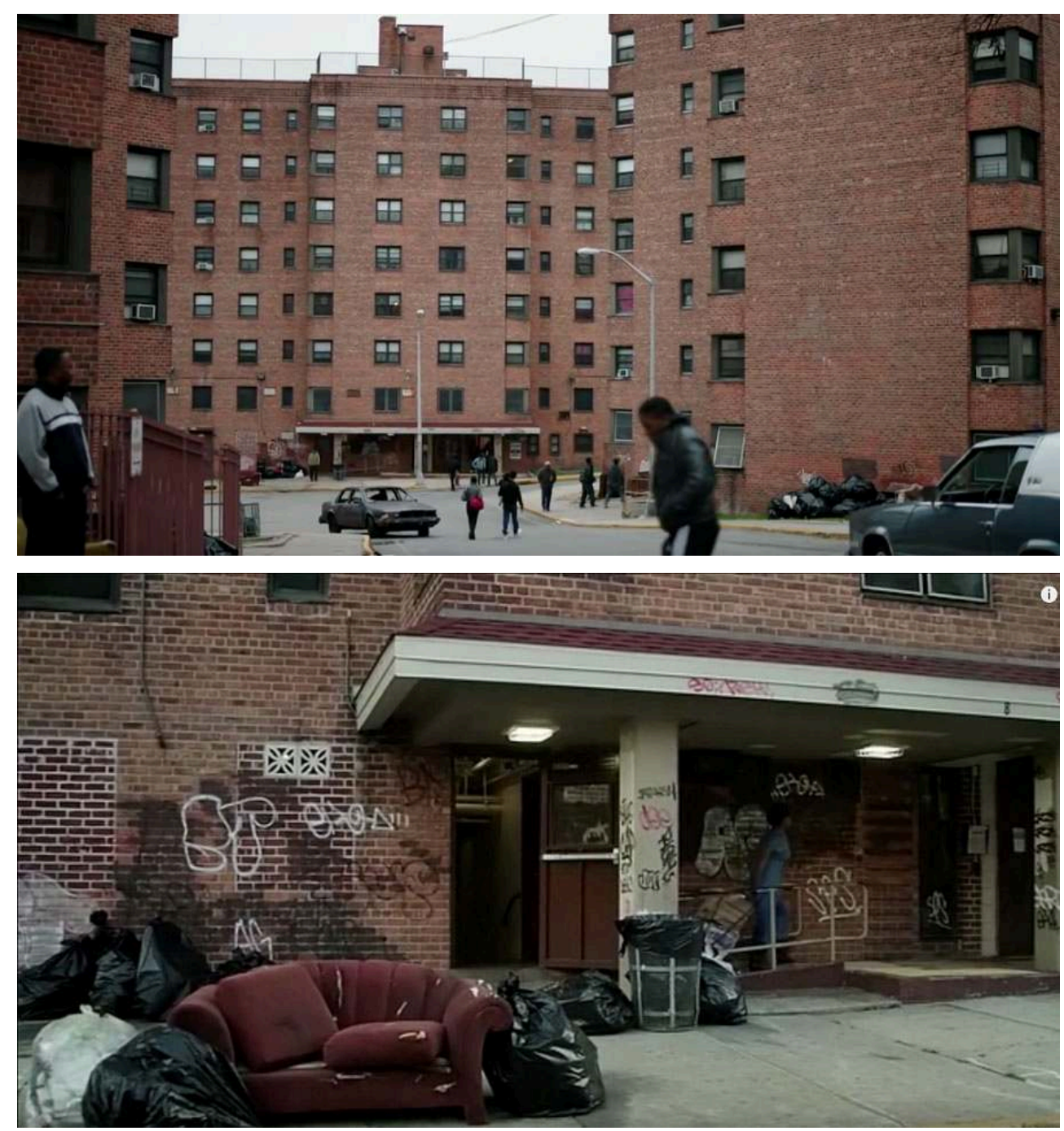

Un « housing project », une politique publique de logement suppose un travail concret et des décideurs. Ils viennent de New York.

26 L'homme qui est monté dans l'hélicoptère prend des images photographiques aériennes. Il cherche des zones vides possibles et les photographient. Ces images vont ensuite devenir des petits post-its sur des cartes et ainsi se dessine littéralement, la politique de logement sous nos yeux. La volonté de dé-ségréger Yonkers vient donc de gens qui vivent loin de l'inconfort de Yonkers, loin de Yonkers, car ce n'est pas si rapide d'aller en train de Yonkers à New York City. Cette contradiction est d'emblée signifiée.

L'homme qui est monté dans l'hélicoptère repère des zones vides les prend en photos et ces zones deviendront les lieux d'implantions des nouvelles maisons. 
Figure 13 : Recherche des implantations (S01E01)

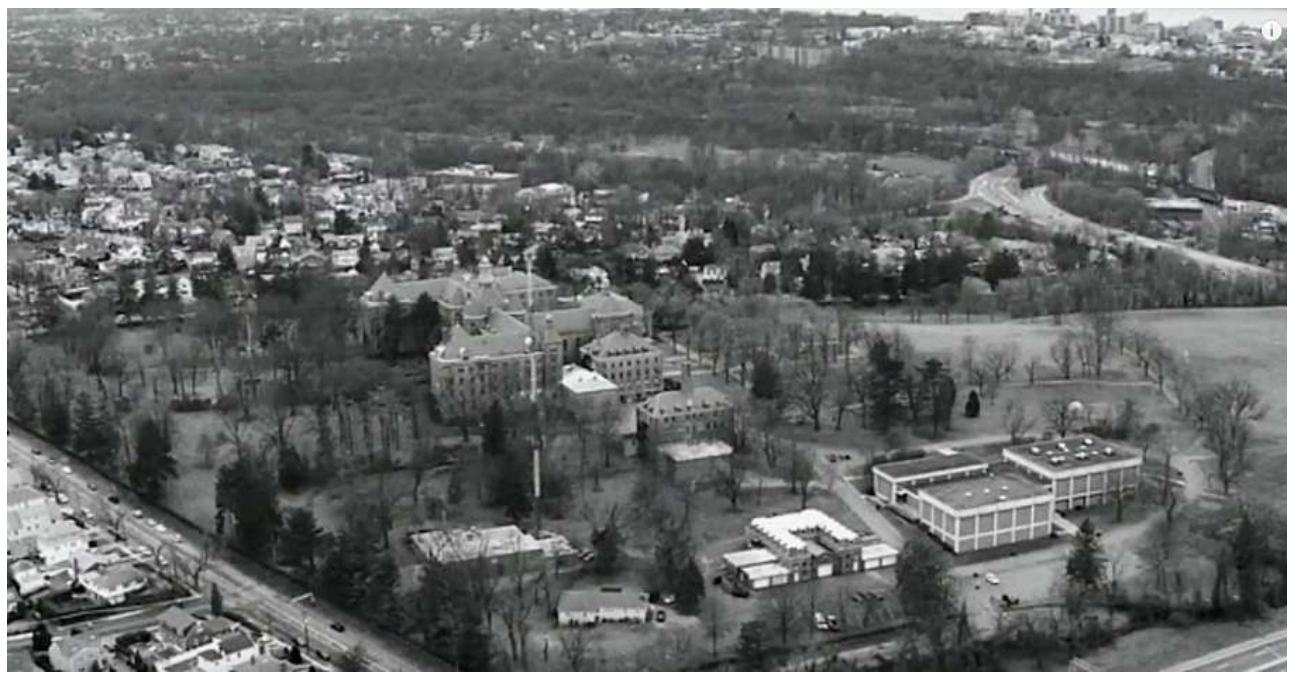

Figure 14 : Carte des implantations (S01E02)

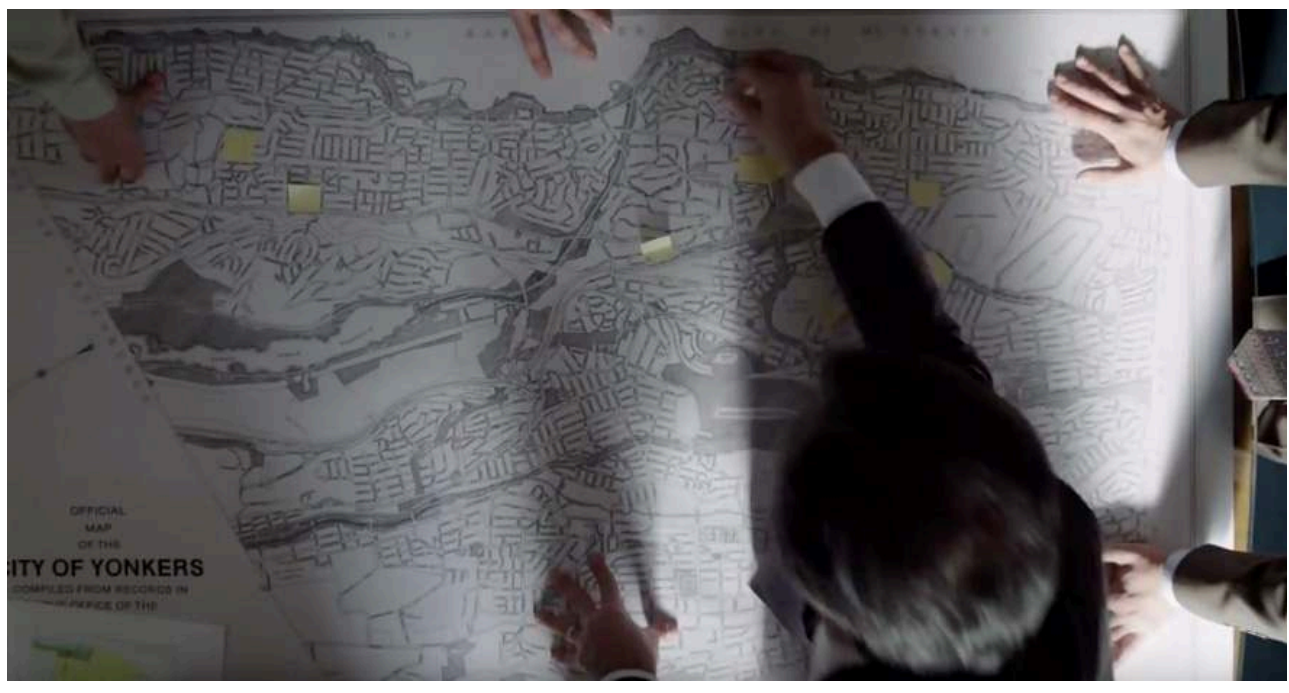

Certes cet homme qui semble tout droit sorti de la jeune Amérique, tant il a l'allure d'un père fondateur avec sa barbe blanche, est un homme bon. Il se soucie de proposer des logements confortables, intelligemment dessinés, pensées en vue du perfectionnement de ceux qui auront le plaisir d'y vivre et de ceux qui en seront voisins. Il explique que ces maisons parce qu'elles sont individuelles conduiront les individus à en prendre soin quand ils délaissaient les espaces collectifs. Sa politique de logement est une politique du care $e^{17}$, quand la construction des cités semblait avoir réglé à moindre coup foncier l'habitat des plus pauvres sans souci sur leur devenir. 
Figure 15 : Dessin d'architecte contemplé par Nick (S01E04)

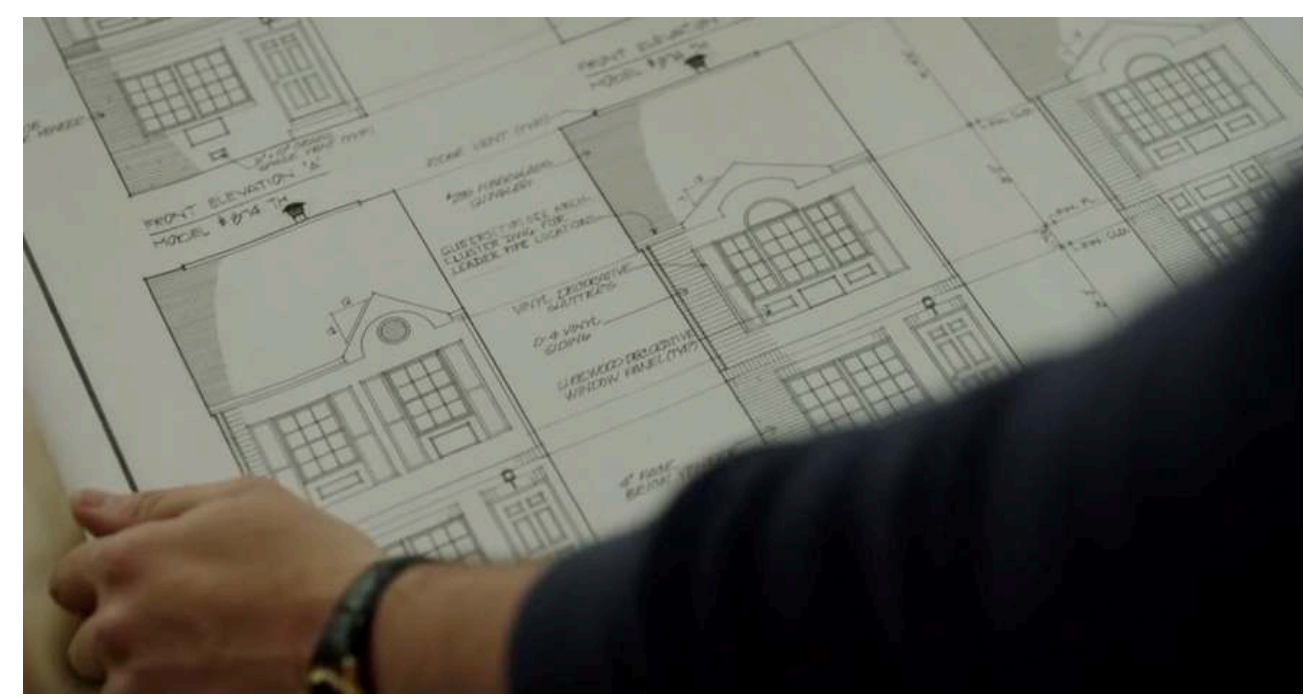

Le "fate " américain a été campé par les images, mais pour que cela fasse vraiment écho, sans doute faut-il quand même être américain ou savoir un peu de quoi relève la vie américaine ordinaire, en avoir fait l'expérience. Savoir qu'un train là-bas n'a pas les mêmes connotations qu'ici, savoir que les maisons en bois sont des maisons ordinaires de premier prix.

Savoir que pour autant, quand on travaille comme simple employé ou simple ouvrier, c'est la seule richesse dont on dispose et que cette maison sert à obtenir des hypothèques pour les grosses dépenses, études des enfants ou fin de vie.

Vouloir trouer cette ville de nouveaux logements, c'est en soi une sorte de révolution, car aucun des quartiers traversés n'est mixte, ni socialement ni racialement. La mixité pourra être vécue comme justice à New York mais comme violence injuste à Yonkers.

Les lois et les « raisonnante projects » ne suffisent pas à déplacer la nappe immobile du temps américain. Les habitants blancs défendent leur bonheur et ne veulent pas du malheur de Schlobohm. L'universalisme, dont les droits civiques relèvent, reste une idéalité qui lie différents rapports de domination. Celle de la grande voisine New York sur Yonkers, celle du gouvernement fédéral sur les gouvernements locaux des villes. Peut-on perfectionner une ville par l'autorité de la loi ?

33 L'homme qui a pris les photos et qui incarne l'idéal du «pursuit of happiness » de la Déclaration d'indépendance américaine, veut utiliser la loi pour donner des moyens concrets à chacun de chercher son bonheur. Et, finalement, qu'est-ce d'autre que le perfectionnisme sinon cette quête qui ne doit pas nier celle des autres? Parce qu'on pense à son bonheur, on peut aussi devenir sensible à ceux qui en ont été écartés et faire chaque jour ce qu'il faut pour que la communauté du «neighbourhood » soit déjà une communauté de bonheurs individuels. Chacun son chez soi, un chez soi qu'on trouve beau, un chez soi qui appelle le soin, le prendre soin. 


\section{3. "The pursuit of happiness " comme mouvement perfectionniste}

34 La figurine d'un petit couple d'amoureux orne le pied d'un arbre pas loin de Schlobohm.

Figure 16 : La figurine all we need is love (S01E02)

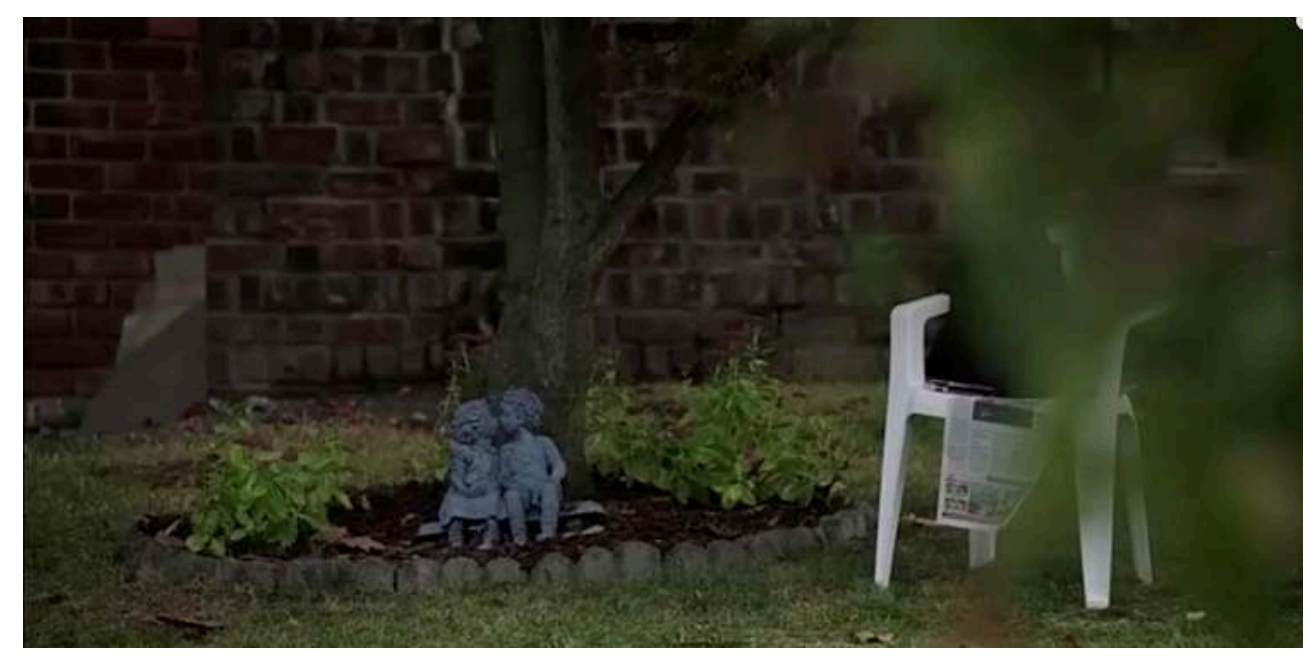

Et la joie toute simple qui est décrite à plusieurs reprises, c'est celle des jeunes gens qui tombent amoureux et qui sont promis à construire un foyer, une famille. C'est le cas de Nick qui rencontre sa femme au travail, ils sont jeunes, gauches et charmants. C'est le cas de Doreen dont les parents ont quitté Schlobohm pour le New Jersey, mais qui alors qu'elle visite sa sœur qui avait voulu y rester, tombe amoureuse d'un gars mignon mais qui deale de la drogue. C'est le cas de Billie qui a quitté l'école contre l'avis de sa mère et tombe amoureuse d'un garçon qui se révèle encore moins intéressant, criminel et infidèle. Stream of love....

36 Et ça tourne mal leur histoire. Le dealer meurt et Doreen, débordée se drogue. Billie ne veut pas comprendre à qui elle a à faire et élève ses enfants avec un père en prison. Nay finit veuve et mettra longtemps à retrouver le fil de la vie.

37 L'amour est une puissance trompeuse, il ne peut venir à bout des malheurs, en tout cas pas toujours, pas tout seul. L'amour est aussi un poison. La dualité Baudelairienne n'est pas si loin. 
Figure 17 : Doreen in love (S01E02)

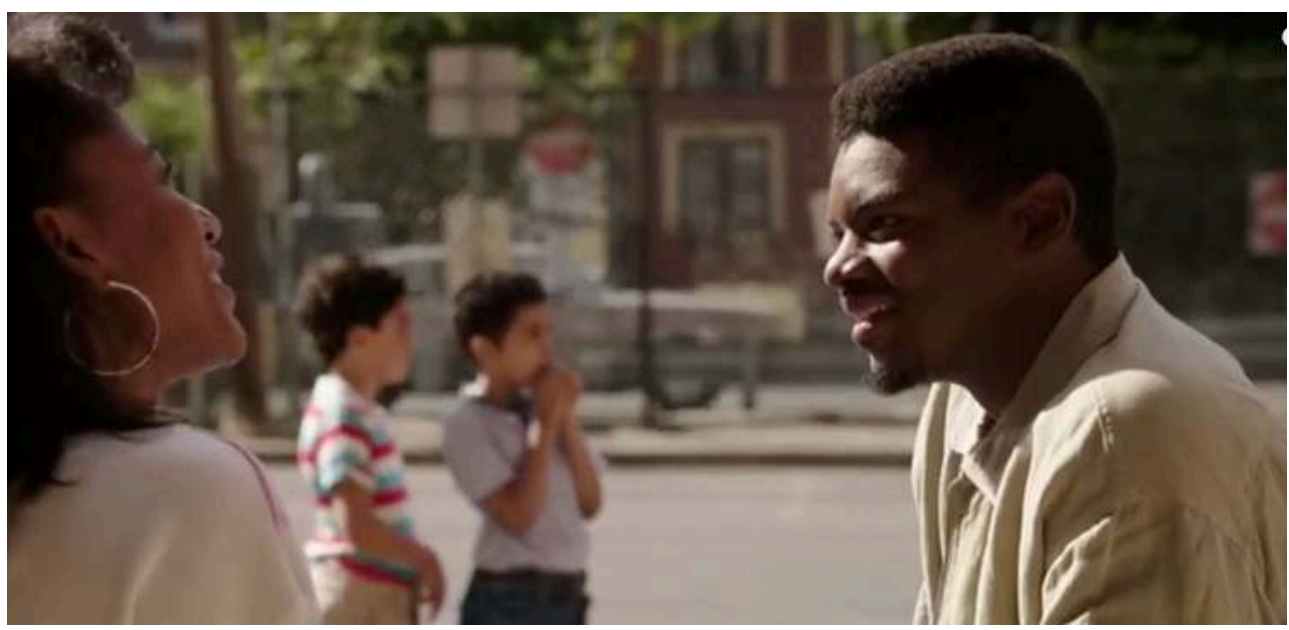

Le couple dans cette série, c'est aussi celui vieillissant de Mary Dorman et son mari. Ils lisent les journaux et regardent la télé ensemble dans un salon douillet et modeste. Ils se parlent avec affection et une relative distance quand même. Elle s'inquiète de ce projet de logements sociaux qui doivent s'implanter dans son quartier. Mais elle mène seule son combat, et c'est comme individu que nous allons la suivre dans sa quête.

Si la figurine dit bien la force des couples dans l'imaginaire du bonheur, de fait la famille est le véritable lieu de l'affection dès lors filiale et non conjugale, et le soutien des femmes seules. Madame O'Neal, l'infirmière aveugle a des enfants qui veillent sur elle. Carmen élève seule trois enfants, et ce sont eux, in fine, qui lui donnent la force d'affronter la vie aux États-Unis. Après avoir imaginé pouvoir les laisser en République dominicaine chez sa mère, elle réunit à nouveau son petit monde autour d'elle. L'hôtesse de l'aéroport la complimente pour cette jolie famille.

Figure 18 : Carmen retrouve ses enfants à l'aéroport (S01E04)

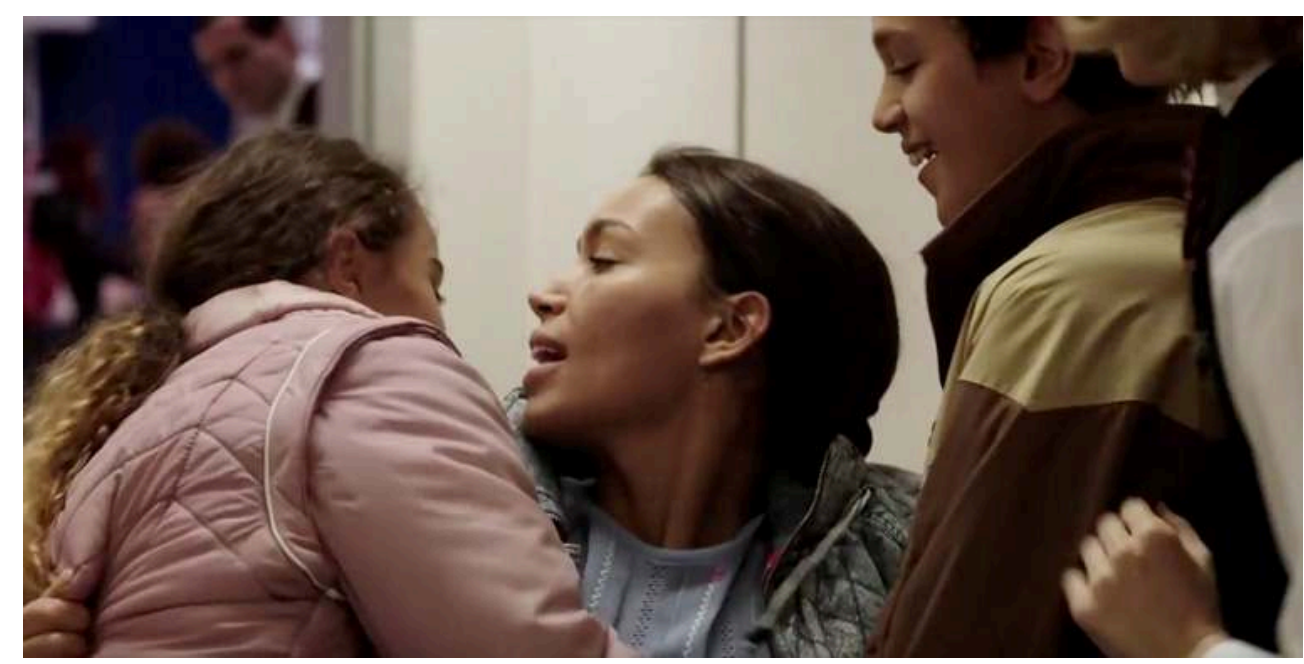

Carmen est une mère-courage. Elle fait l'épreuve de la séparation d'avec ses hommes, puis d'avec ses enfants pour in fine mieux consolider ses choix, travailler dur aux ÉtatsUnis, mais ainsi avoir des enfants américains ou qui le deviendront. Elle les aimerait protéger de la violence de Schlobohm, demande à participer au programme de relogement. Ce sera injustement long, mais couronné de succès. La dualité qui 
caractérise chacun des personnages de cette série est peu nuancée ici, mais le personnage montre comment la vie sensible vient arbitrer plus que les arguments intellectuels qui déchirent le cœur, même s'ils sont raisonnables.

Figure 19 : Carmen laisse ses enfants en République dominicaine, la mort dans l'âme (S01E02)

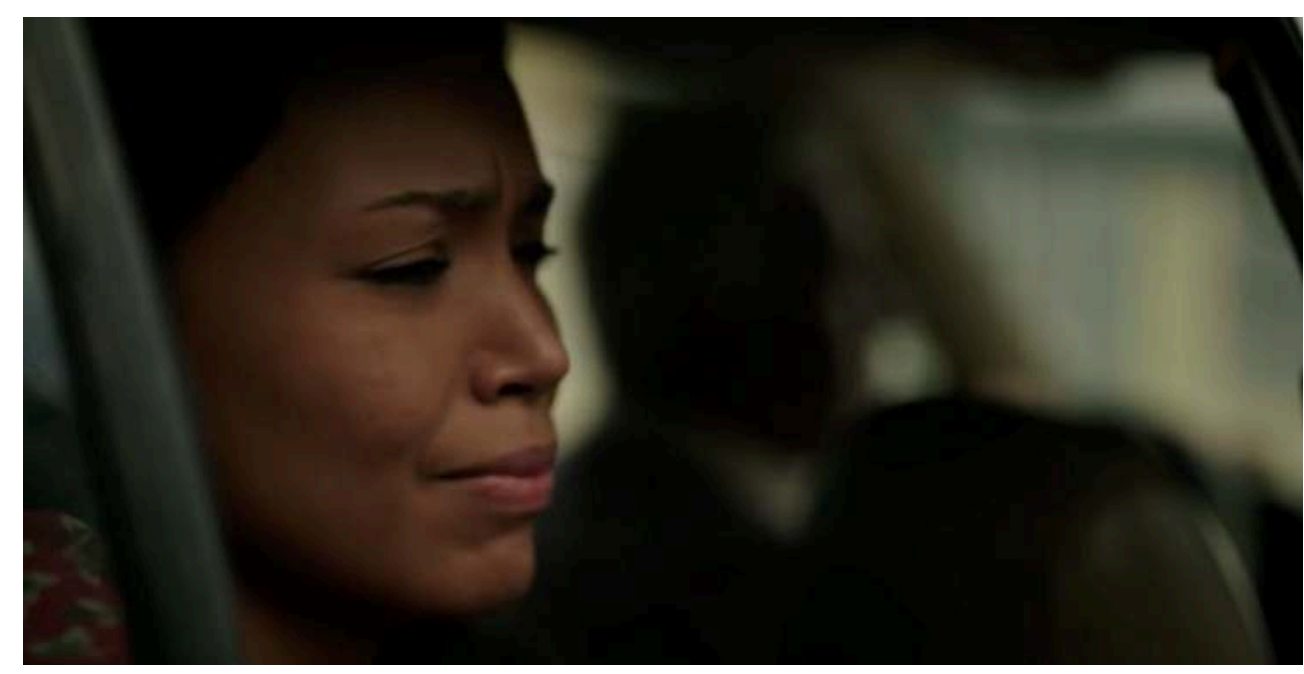

Carmen est entière et très droite. Elle prend des décisions puis la vie la travaille de l'intérieur. Ses enfants lui manquent comme l'air dans les poumons et elle doit donc décider d'entendre son cœur et faire cesser cette douleur et les faire revenir. Elle incarne cependant la violence des choix à faire pour laisser apparaître les puissances de vie. Son métier consiste à faire revivre des vieux meubles, elle les décape, décroche les vieux chewing gum collés, et porte un masque pour ne pas être brulé par l'acide. C'est elle qui ouvre et ferme chaque jour son atelier, et chaque geste est en soi un symbole de son courage, de son énergie.

Figure 20 : Carmen sur la défensive (S01E03)

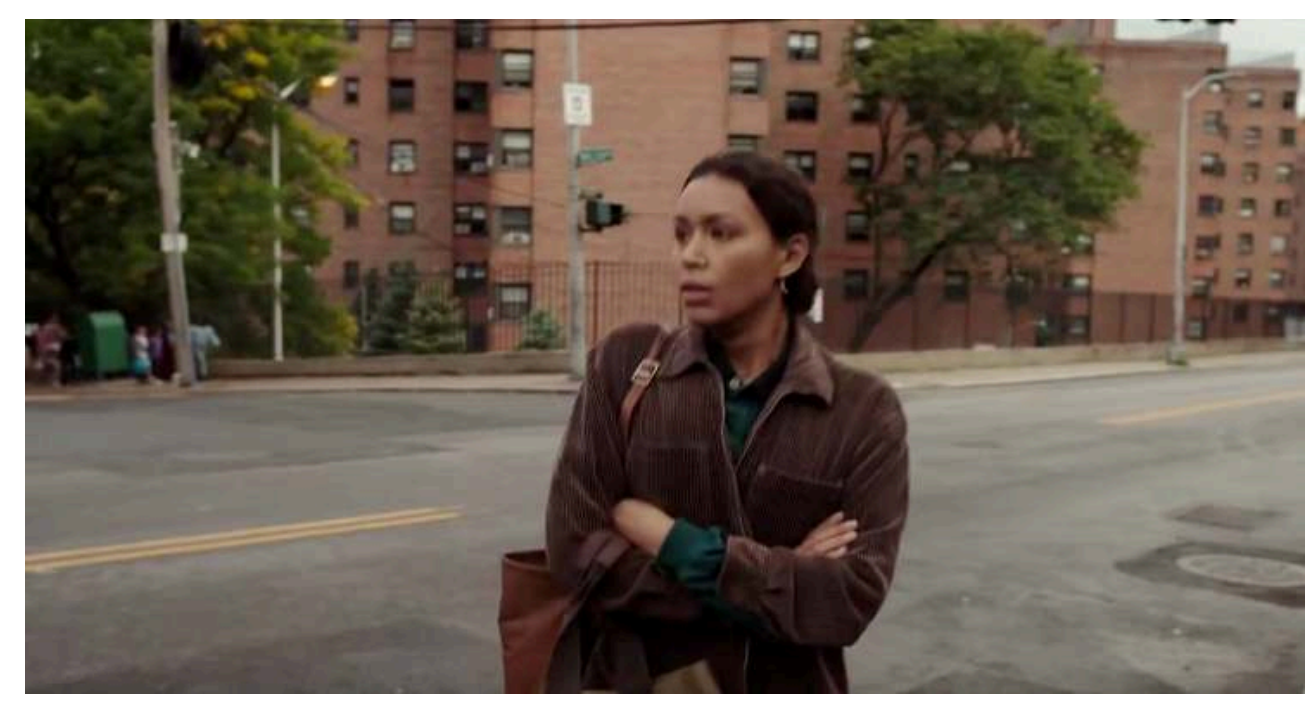


Figure 21, 22 et 23 : Carmen au travail (S01E03)
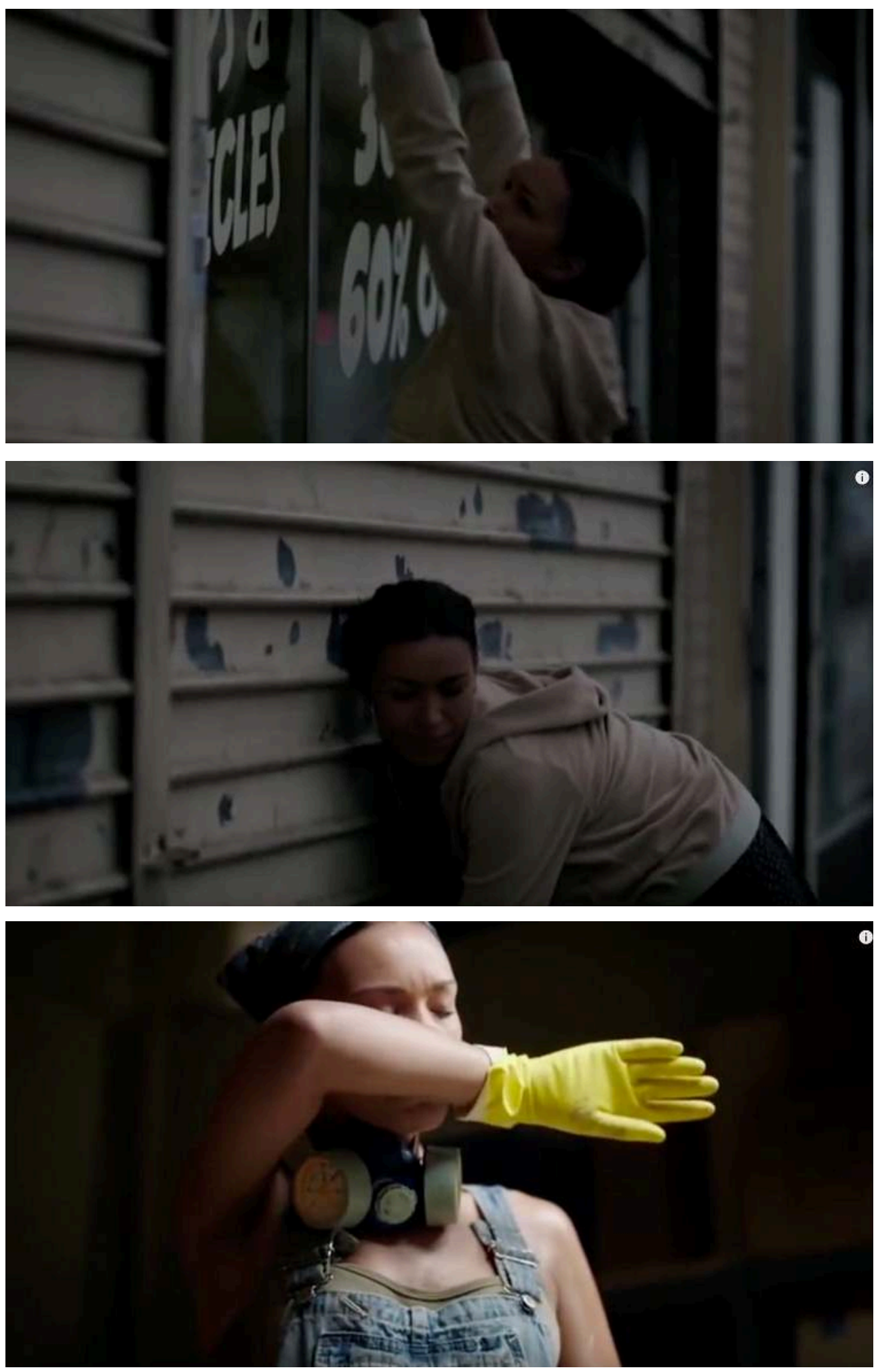

42 L'enjeu des « housing projects » dans Show Me a Hero semble ainsi faire prospérer cette solidarité familiale et permettre aux femmes (seules) de trouver dans leur «neigbourhood » un espace de solidarité quasi-familial pour elle et leurs enfants.

43 La solitude est montrée comme plus grande dans les grands ensembles, les cités comme Schlobohm que dans les quartiers de petites maisons individuelles. Pour faire 
communauté, il faut d'abord s'être ressaisie soi même comme individu. Pour Carmen, en quelque sorte cette part là est déjà là. C'est une femme souveraine qui sait s'écouter, penser, protéger, bifurquer, conduire sa vie.

Figure 24 : Le nouveau quartier à la fin du processus (S01E06)

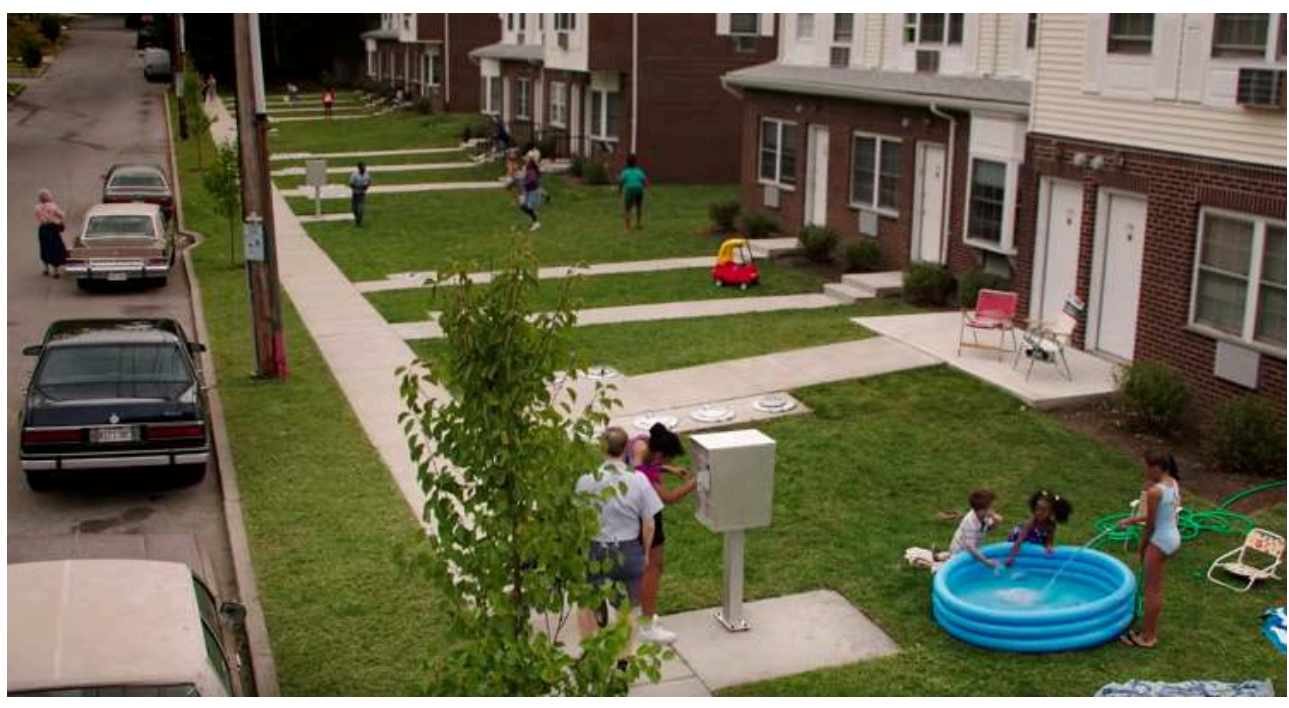

Si les histoires de bonheur dans Show Me a Hero sont des histoires de chute et de rédemption, pour Carmen, il n'y a pas de chute, juste une décision trop intellectualisée de protéger ses enfants en les laissant loin d'elle. Il faut juste redonner de la place à sa confiance en elle, et replacer son désir de protection des siens au bon endroit.

Je voudrais maintenant m'attarder sur deux histoires qui s'entrecroisent : celle de Mary et Doreen. Ces deux femmes permettent non seulement de faire les portraits d'individus qui se perfectionnent en cherchant leur bonheur, c'est-à-dire leur puissance de vie, mais encore le portrait d'une communauté urbaine qui se perfectionne.

Doreen quitte le New Jersey parental, fait un enfant avec un père qui meurt avant même que l'enfant ne soit né, se retrouve parfaitement démunie face à ce qui lui arrive, se drogue, et dans cette série finit par devenir un personnage clé de la communauté du " project».

Mary qui hurle avec les loups blancs dans le hall municipal pour refuser les « housing projects » et réclamer qu'on fasse encore appel contre le jugement de la cour suprême, et qui finit par rayonner en vivant non plus sa petite vie personnelle mais une vie pleine d'interactions et de liens dans cette communauté mixte.

Dans l'un et l'autre cas, les visages sont les lieux où la fiction nous convie à vivre par procuration le perfectionnisme dans ses hésitations, ses aléas, ses épreuves, car les visages disent l'âme chère à Stanley Cavell, visages-paysages ravagés ou lumineux. Sans l'image propre à la série, nous, spectateurs, ne pourrions être autant inspirés et touchés par ces personnages de fictions. 
Figure 25 : Doreen et Mary, symboles de la réussite du projet (S01E06)

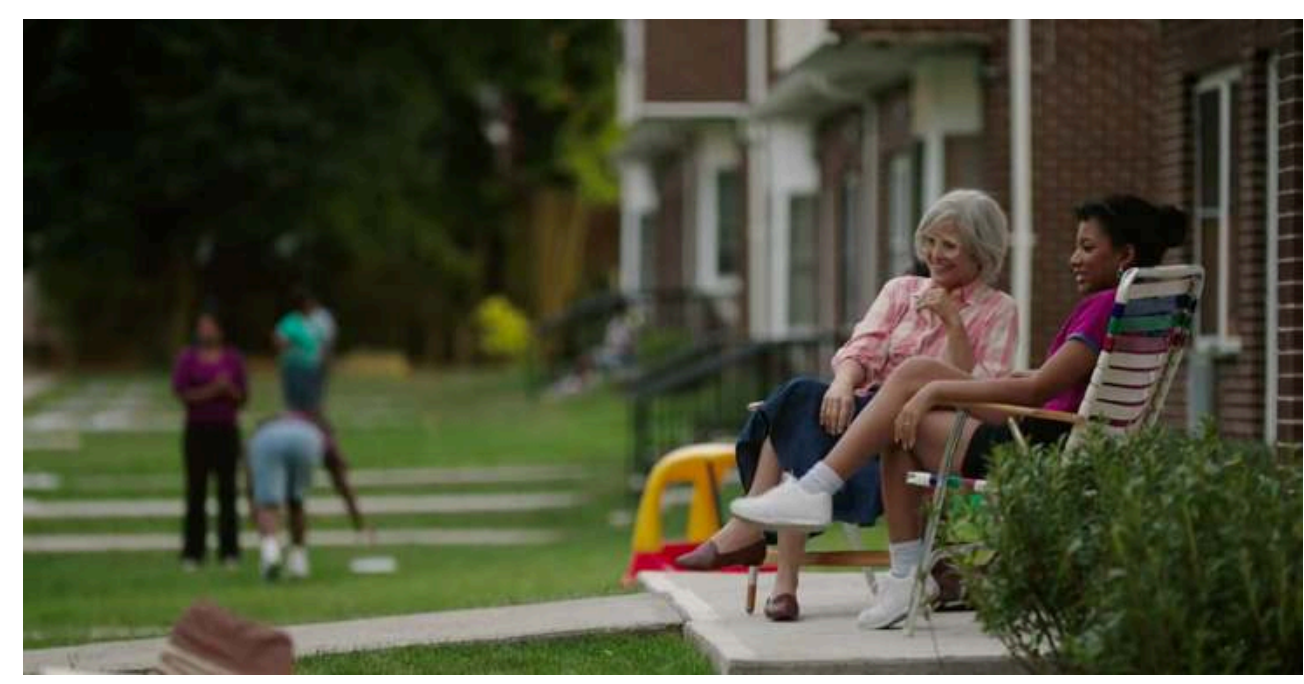

Les inflexions des sentiments, de la faculté de juger, de décider, de penser, passe d'abord par ces visages en proie à la liberté d'agir et aux dilemmes de cette liberté. L'image filmée qui rencontre nos propres sentiments à l'écoute, fonctionne comme la musique pour le danseur, contrairement à la conversation ou à la lecture, il n'y a pas de tac au tac, mais un seul tac ${ }^{18}$, qui nous touche en direct émotionnellement et nous conduit ainsi à produire notre propre réflexion, notre propre sensibilité raisonnante. Le visage est le lieu d'une communication communiante des expériences.

\section{Visages du perfectionnisme, unité et dualité}

Le cinéma muet avait fait de chaque émotion un code à imprimer sur le visage de l'acteur ou de l'actrice, la physiognomonie n'était pas loin avec ses archétypes. Le parlant en adoptant des codes réalistes rend plus ténue, l'expression des sentiments et bien jouer, c'est donner et de sa personne et de son âme, pour que son visage soit affecté par les sentiments du personnage, au point de les faire ressentir dans leur fugacité au spectateur. Paradoxalement, ce caractère ténu et fugace donne plus de force à l'expression des sentiments. Or, dans Show Me a Hero, les sentiments sont des facultés d'éprouver et ainsi d'être vivant, souffrant ou rayonnant, mais aussi de juger, de faire expérience et de se perfectionner. Le visage de Doreen est d'abord rayonnant dans la joie de l'indépendance et de l'état amoureux, puis elle se met à douter de ce que lui raconte son compagnon. Tout au long des épisodes deux et trois, son visage ne va cesser de se décomposer d'abord quand elle apprend la mort du père de l'enfant qu'elle porte encore, en larmes, hagarde, perdue, puis elle se noie malgré l'enfant venu. 
Figure 26 : Doreen doutant de son compagnon (S01E02)

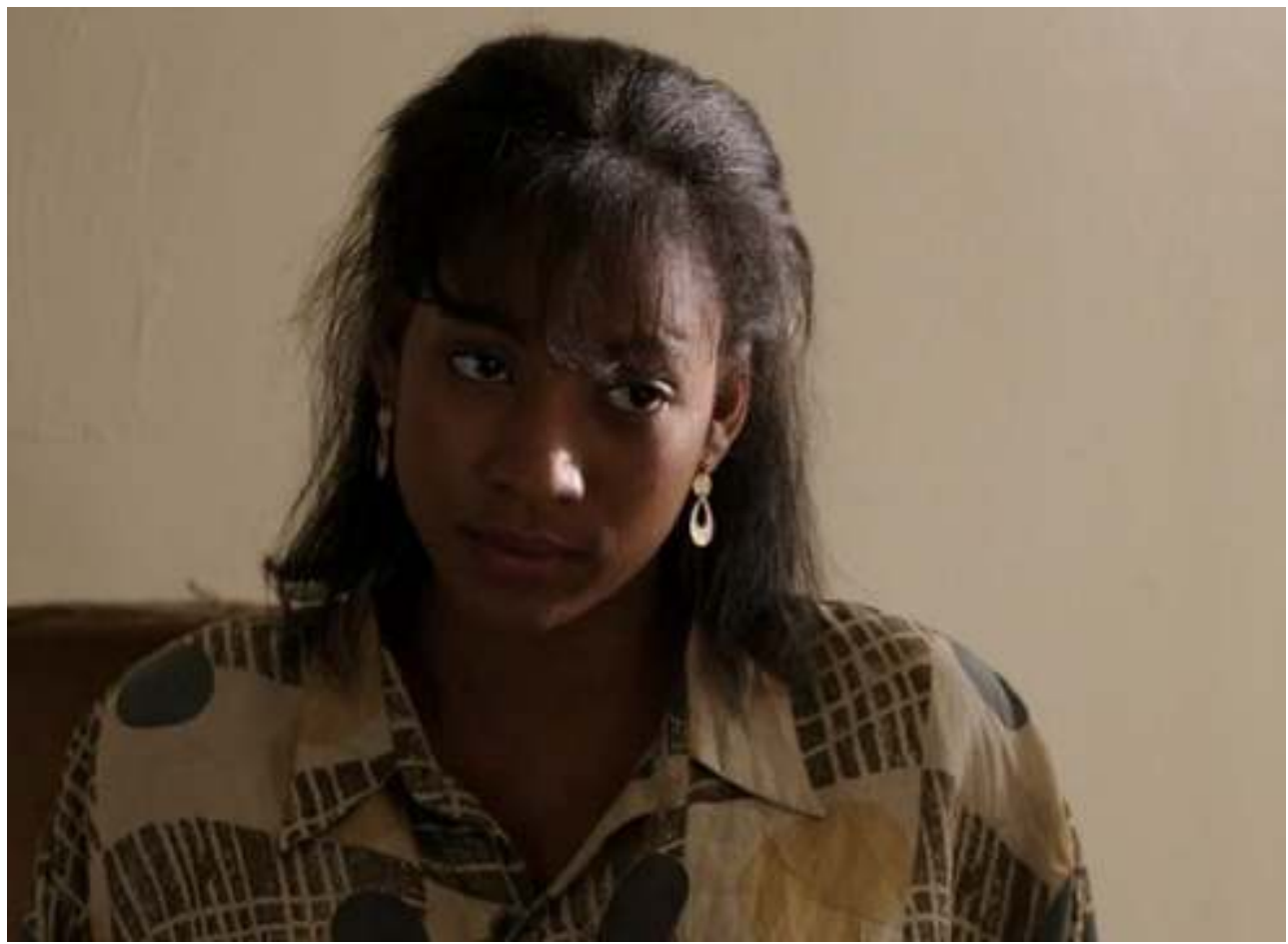

Figure 27 : Doreen apprenant la mort de son compagnon et ne sachant plus quoi faire (S01E02)

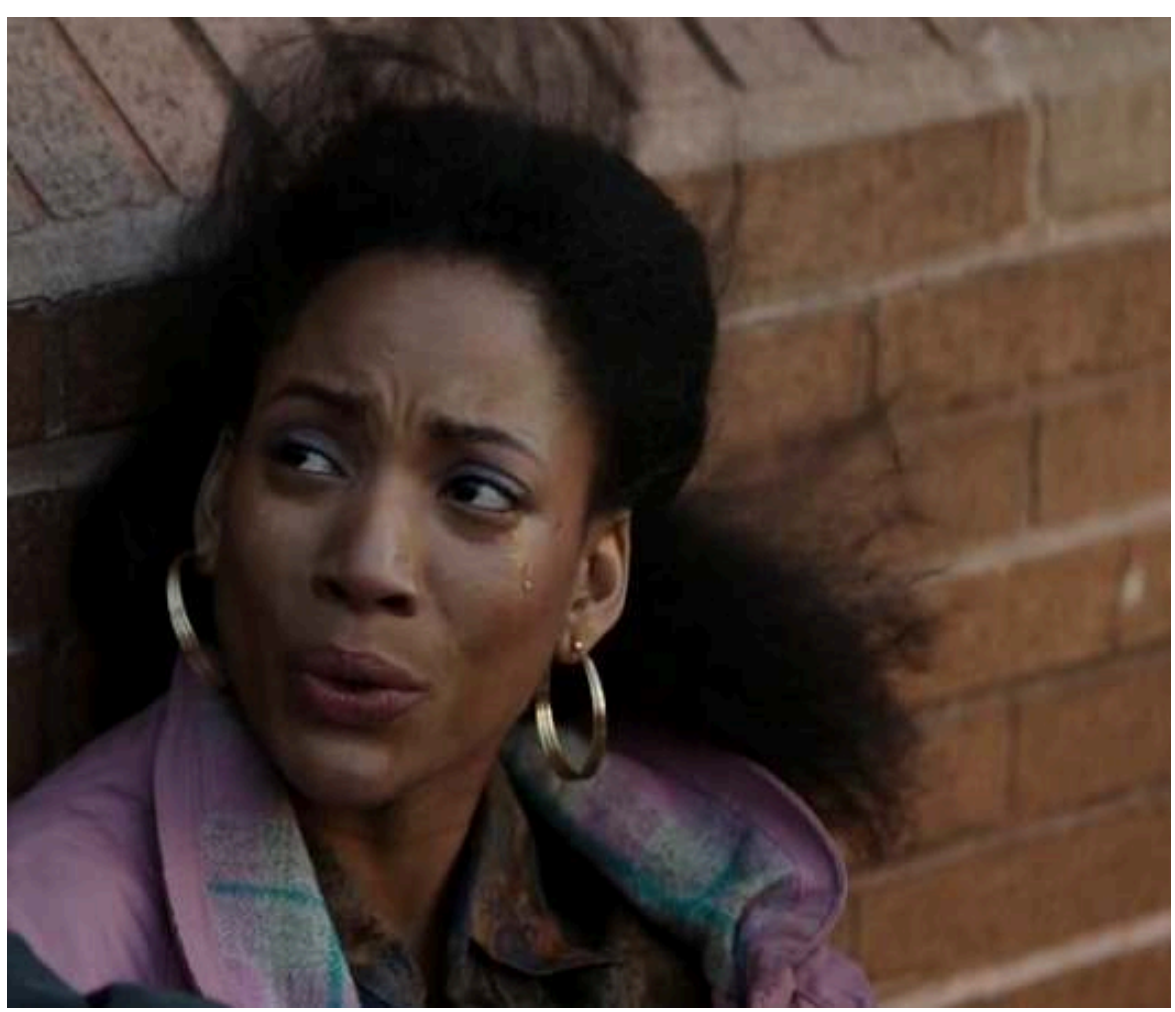

51 La rencontre avec les services sociaux qui lui expliquent qu'elle peut accéder à un logement lui fait sortir la tête de l'eau mais pour mieux replonger, elle n'assume pas sa situation. 
Figure 28 : Doreen rencontre les services sociaux qui la logent à Schlobohm (S01E03)

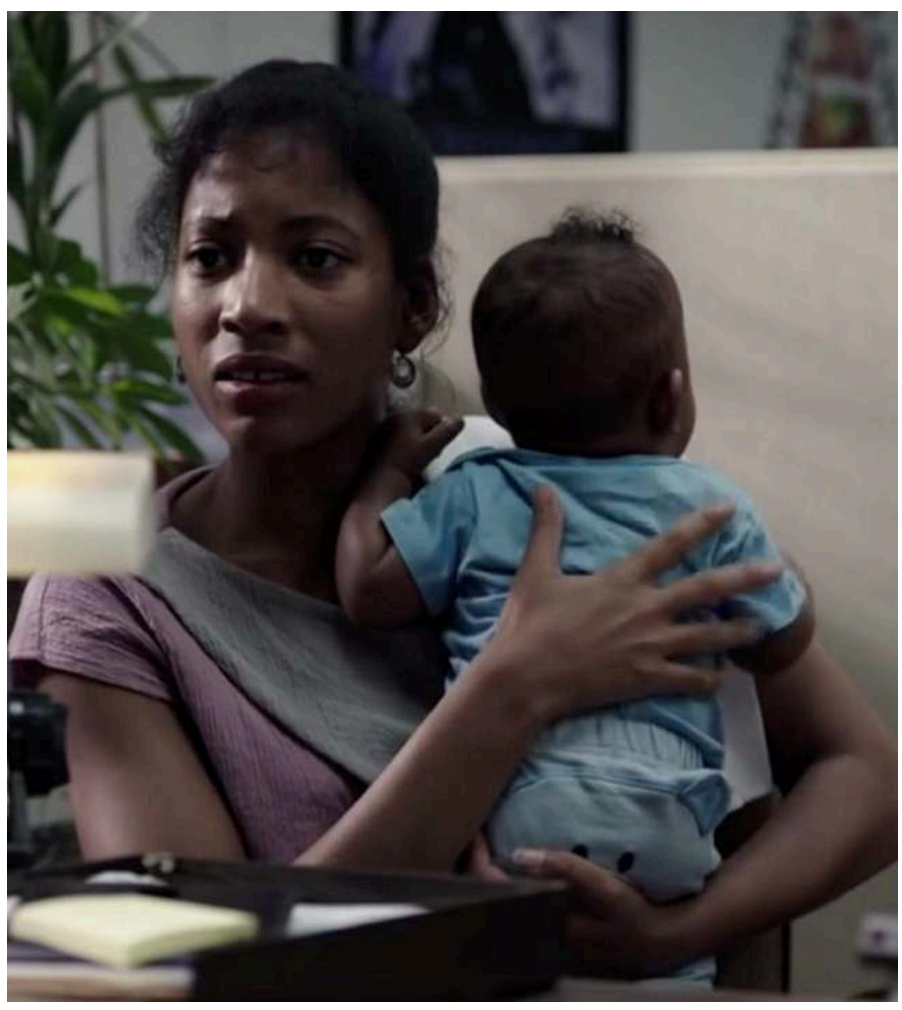

52 Son père, qui vient la visiter, s'en rend compte, il lui propose de l'aide, qu'elle refuse. Doreen est encore rebelle malgré sa détresse. Mais un cercle vicieux est enclenché. Elle n'a bientôt plus l'argent de la drogue dont elle est devenue dépendante.

Figure 29 : Doreen rebelle et droguée (S01E04)

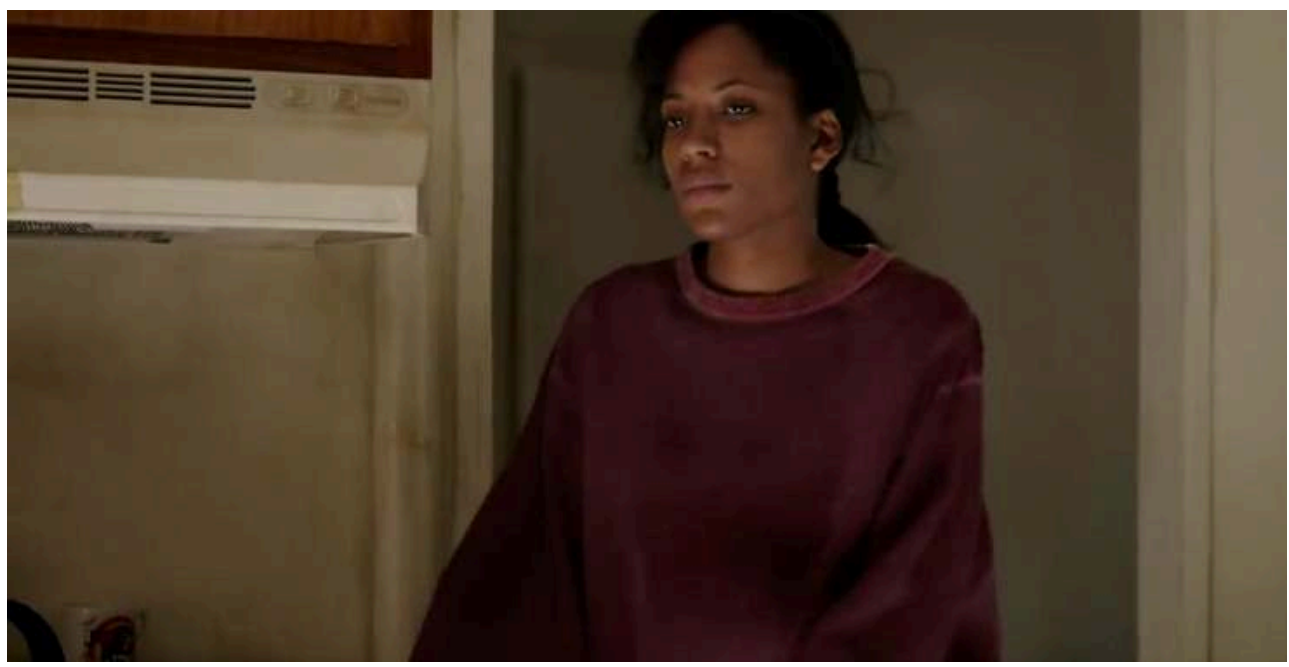

En échange de la drogue et à défaut de l'argent qu'elle n'a pas, le dealer lui propose une passe, la prostitution comme ultime solution. 
Figure 30 : Vers la prostitution ? (S01E04)

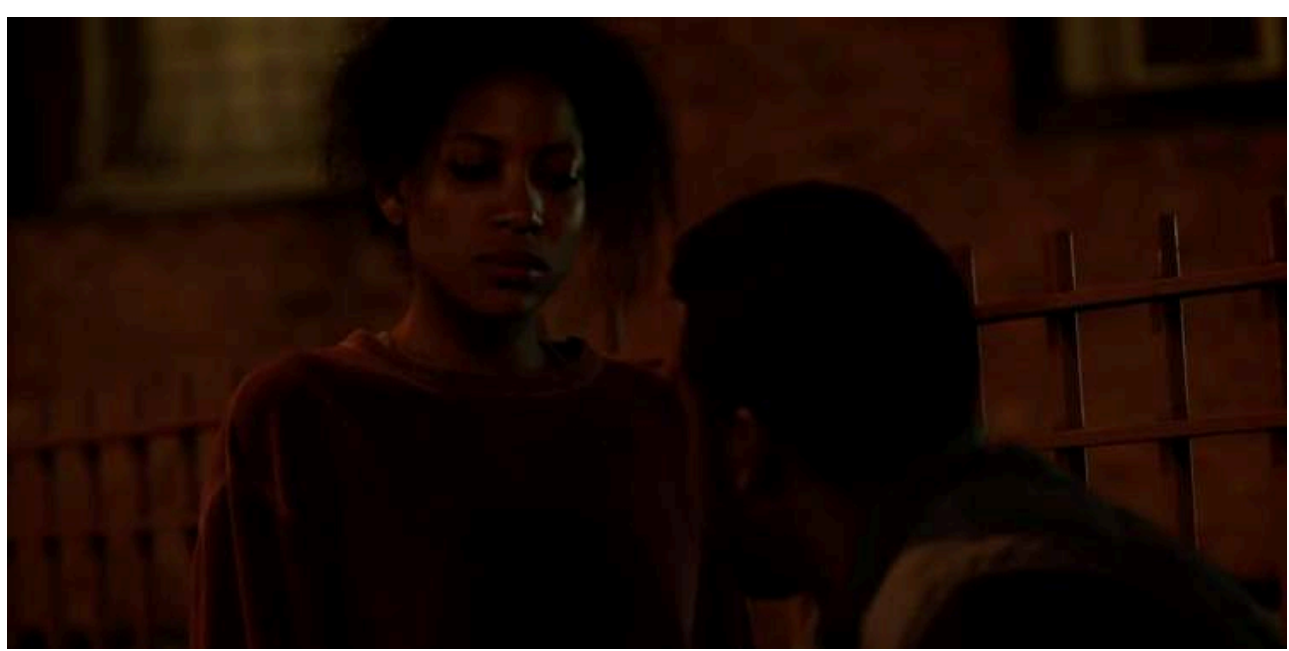

Á ce moment précis surgit la nécessité de retrouver une estime de soi et cette nécessité fait s'effondrer la rébellion à l'égard de la famille. La stupeur vécue au coin de la rue est suivie des larmes dans l'appartement et de la capacité rédemptrice à accepter de demander enfin l'aide proposée par ses parents. Le moment est cathartique. Un gardefou a joué.

Figure 31 : I need to go home (S01E04)

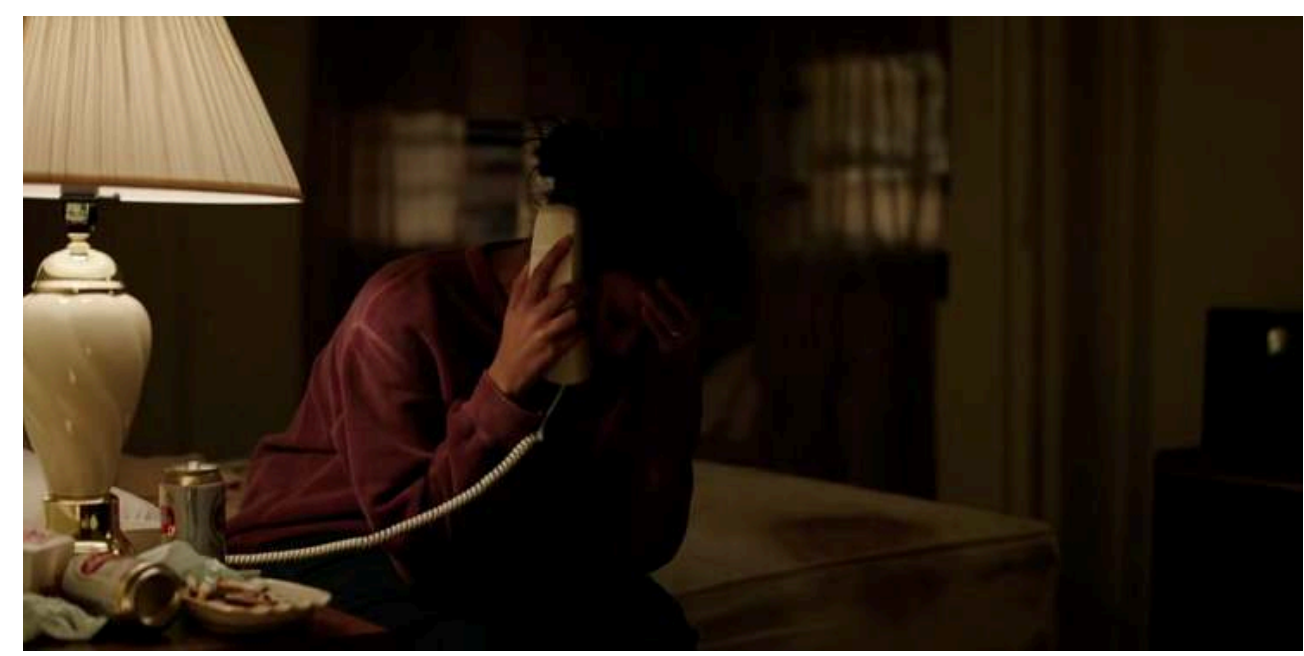

C'est alors la famille qui permet une fois encore la rédemption. De fait, la série est vraiment familialiste, car le home c'est toujours la famille et non les amis, en fait défaillants le plus souvent dans cette série que ce soit d'ailleurs pour Nick ou pour d'autres personnages. "Home " permet à la jeune femme de redevenir responsable pour elle d'abord, puis pour autrui. Elle joue un rôle majeur dans l'organisation nouvelle de la communauté d'habitants qui déménage dans les nouvelles maisons. Les visages émus sont passés de la jeune adulte rebelle, de la jeune mère perdue, à la droguée méprisée, pour enfin retrouver une jeune femme inquiète et faisant son chemin avec son enfant dont elle prend grand soin. Cet enfant figure son envol. Il joue à faire l'avion dans la « back yard » alors qu'elle le cherchait partout. 
Figure 32 : Jaron dans sa back yard (S01E06)

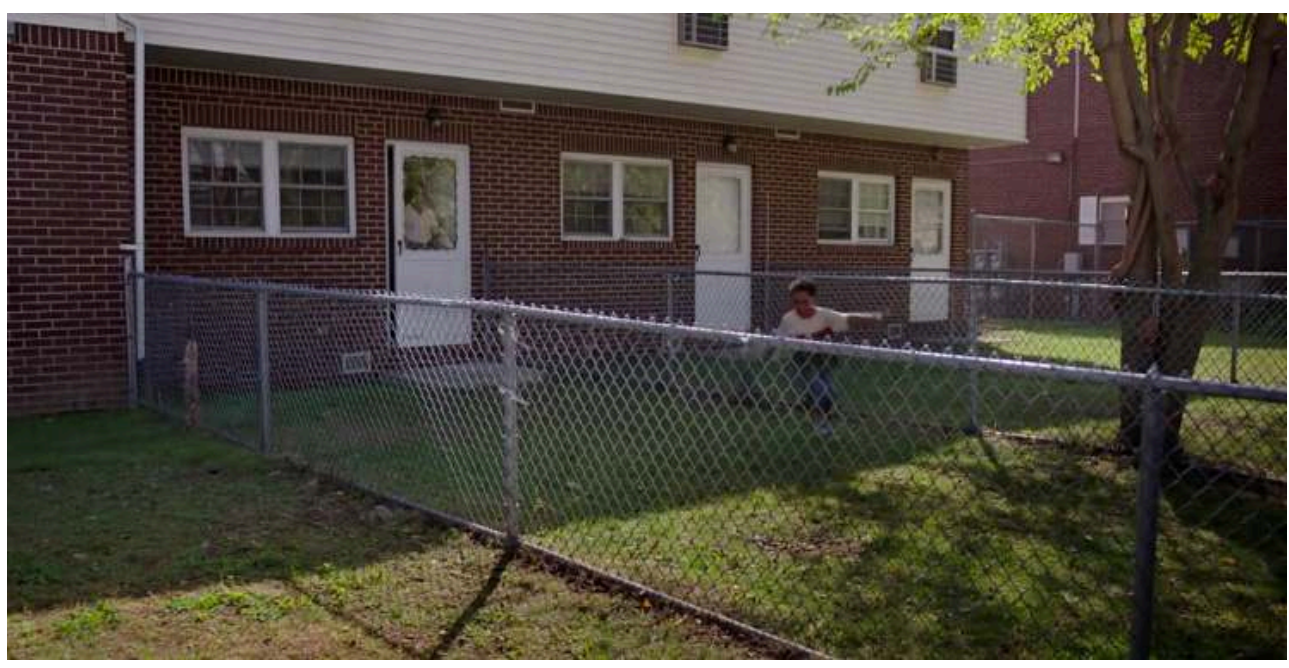

Il est chez lui, elle est à la fois soulagée et fière d'elle, encore fragile de l'expérience traversée, mais vaillante aussi dans sa fonction de chainon dans l'organisation de la " community». Son visage changeant aura exprimé non pas la contrainte sur les puissances de mort, mais bien la libération des puissances de vie ${ }^{19}$.

On pourrait dire que c'est moi seule qui met sur ces visages les énoncés proposés et cette philosophie morale liée à la lecture que Cavell fait d'Emerson et de sa double polarité. Mais le visage est le lieu qui permet de montrer l'unité et la division, le même et le changement, la personne et son lien au monde. Il est aussi, grâce au gros plan, au cadrage, au champ-contrechamp, le lieu de ce contact créatif avec le public, car un visage ne dit pas de derniers mots, il est matière vivante de l'être et à ce titre la conversation, ou la dimension de "fiction délibérative " que constitue une série selon la belle expression d'Emmanuel Taieb $^{20}$, commence par notre capacité à observer, à recevoir ces visages qui vivent et pensent. Á recevoir le travail des acteurs qui prenant soin des personnages qui leur ont été confiés nous aident nous aussi à nous perfectionner. Ici revenir peut-être sur le sentiment que cette jeune femme victime de la drogue de Schlobohm, de son mari qui la lui laisse comme seul héritage pour l'enfant à élever, était définitivement perdue. La série peut conduire à comprendre que les puissances de vie peuvent être tout aussi fortes que les puissances de mort, mais qu'il y faut un premier point d'appui. Comprendre que l'abjection d'une question peut produire un sursaut, les visages de Doreen nous font croire en l'impossible, c'est-à-dire en la métamorphose. La croyance au devenir pourrait être l'autre nom d'une attention au perfectionnisme à l'œuvre. Et c'est à cette croyance que la trajectoire de vie de Doreen, médiée par ses visages, nous fait adhérer. Ce trajet de vie encore une fois doit peu de choses, voire rien, à la dispute intellectuelle et peut-être tout à l'expérience morale sensible. Doreen voulait être indépendante mais elle ne gagne son indépendance qu'en y renonçant momentanément pour libérer sa capacité à devenir responsable. Là réside pour elle la puissance de vie. Redevenue vivante et suffisamment solide, elle peut enfin quitter le domicile familial dans de bonnes conditions, sans rébellion cette fois, mais dans la gratitude et avec une décision ferme. Si deux polarités, l'une bonne et l'autre mauvaise, s'inscrivent en chaque être humain dans une tension existentielle, elle est ici sublimée par une véritable transformation. Cette duplicité, pour Cavell comme pour Emerson qu'il analyse, produit justement la possibilité d'une 
éthique perfectionniste. On retrouve cette tension existentielle dans l'histoire de Mary et dans les visages que l'actrice lui compose. Mais cette dualité est d'emblée prise dans l'enjeu collectif.

\section{Enfourcher la déité, Mary Dorman}

Mary est d'abord inquiète de voir sa vie douillette perturbée par « des gens qui ne vivent pas comme nous ». C'est ainsi que le leader des blancs en colère évoque la population noire de Schlobohm. Elle aussi veut protéger son petit bonheur car elle le croit sincèrement mis en danger, et c'est pour cette raison que finalement elle se met à faire de la politique. Ce n'est pas par civisme mais par intérêt bien compris qu'elle fait donc alliance avec d'autres mécontents de la politique de Nick Wasicsko.

Nous la voyons ainsi manifester puis vociférer littéralement dans le hall municipal où s'affrontent le maire et son opposant Spallone. Ce dernier a attisé le feu en serrant des mains des manifestants à l'ouverture de la séance, mais elle est bien dans ce contexte, la flamme qu'il faut éteindre, c'est-à-dire faire sortir de la salle car elle a insulté le maire.

Figure 33 : Expression de désapprobation puis rictus de Mary (S01E02)

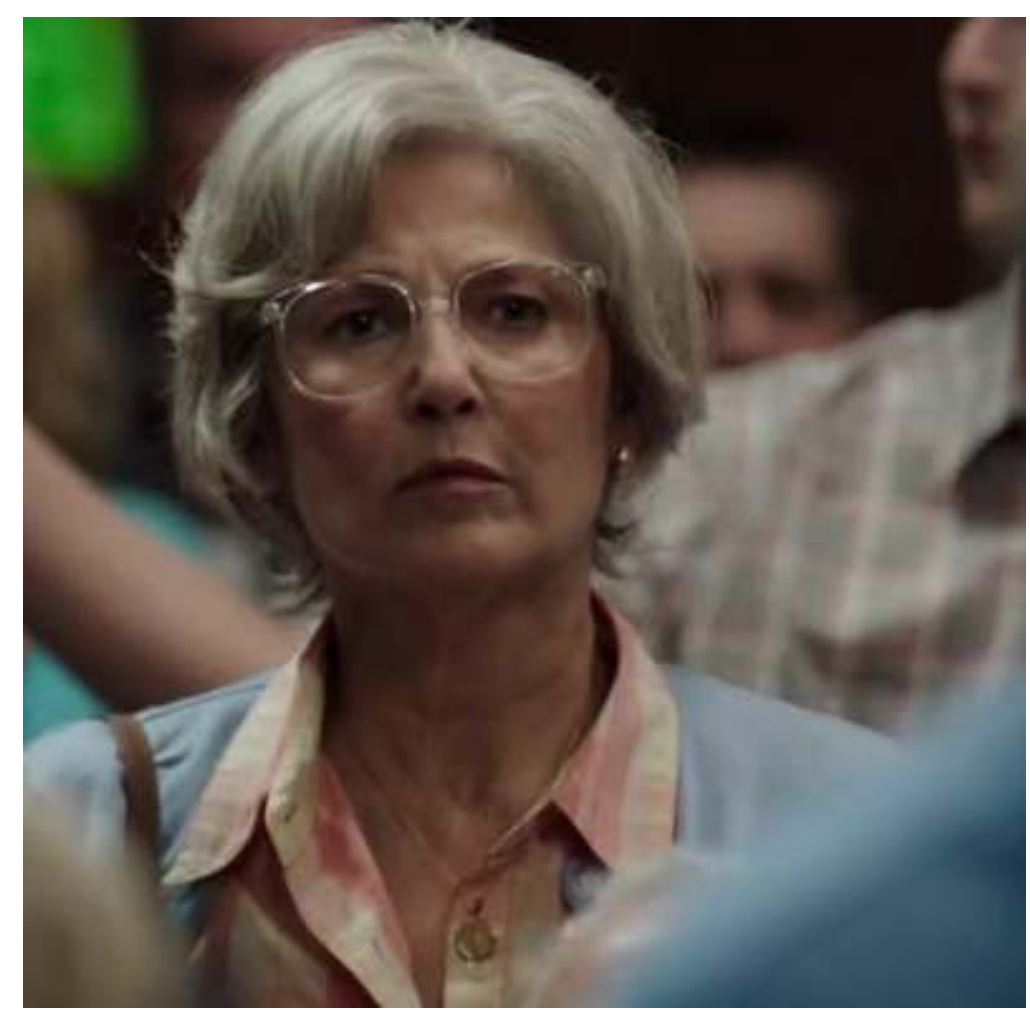



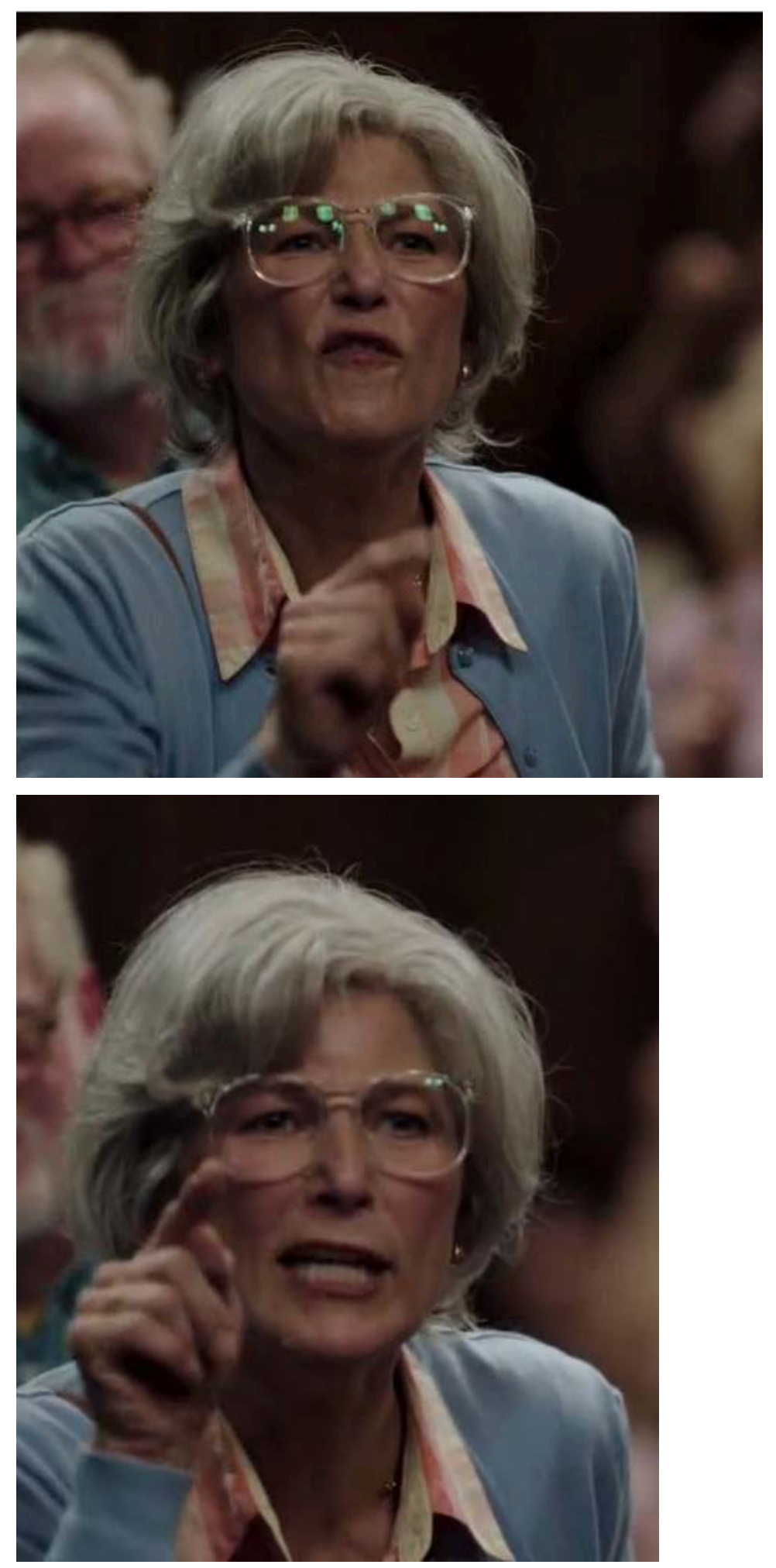
Figures 34 et 35 : Mary évacuée par la police à la demande du maire (S01E02)
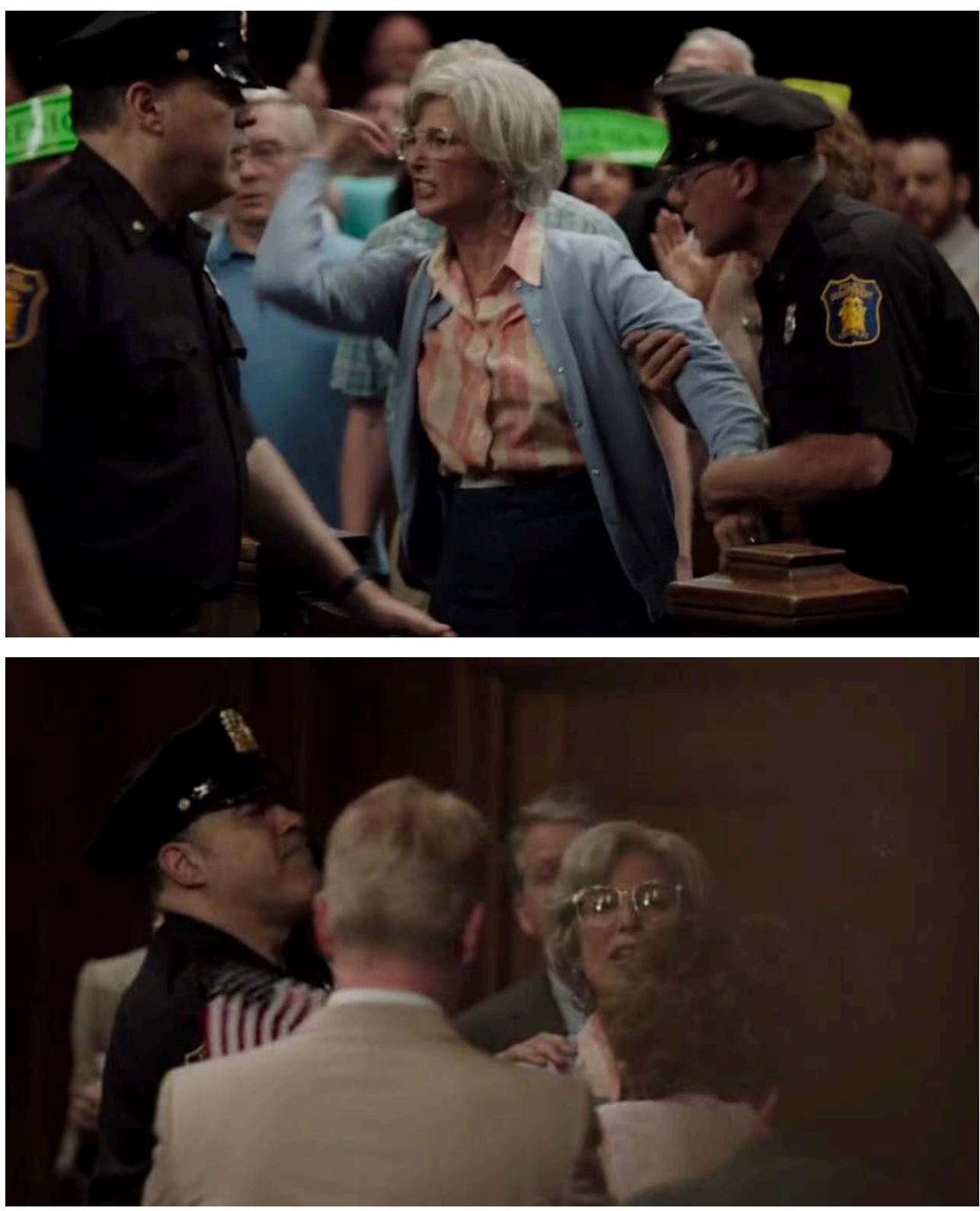

On pourrait, face à un tel visage, porter un jugement définitif en tant que spectateur « leftist », mais nous venons aussi de la voir dans une autre altercation. Cette fois pour dire qu'il ne fallait pas mêler les questions religieuses à cette question du logement social. Alors qu'elle faisait la queue, elle a entendu quelqu'un faire des réflexions antisémites et s'en prendre physiquement à l'architecte qui venait aussi à cette séance décisive du conseil municipal. Son visage est alors pensif et désapprobateur. Ça ne lui plait pas qu'on s'en prenne à l'architecte comme « juif ». 
Figure 36 : Désapprobation silencieuse de l'antisémitisme vu et entendu (S01E02)

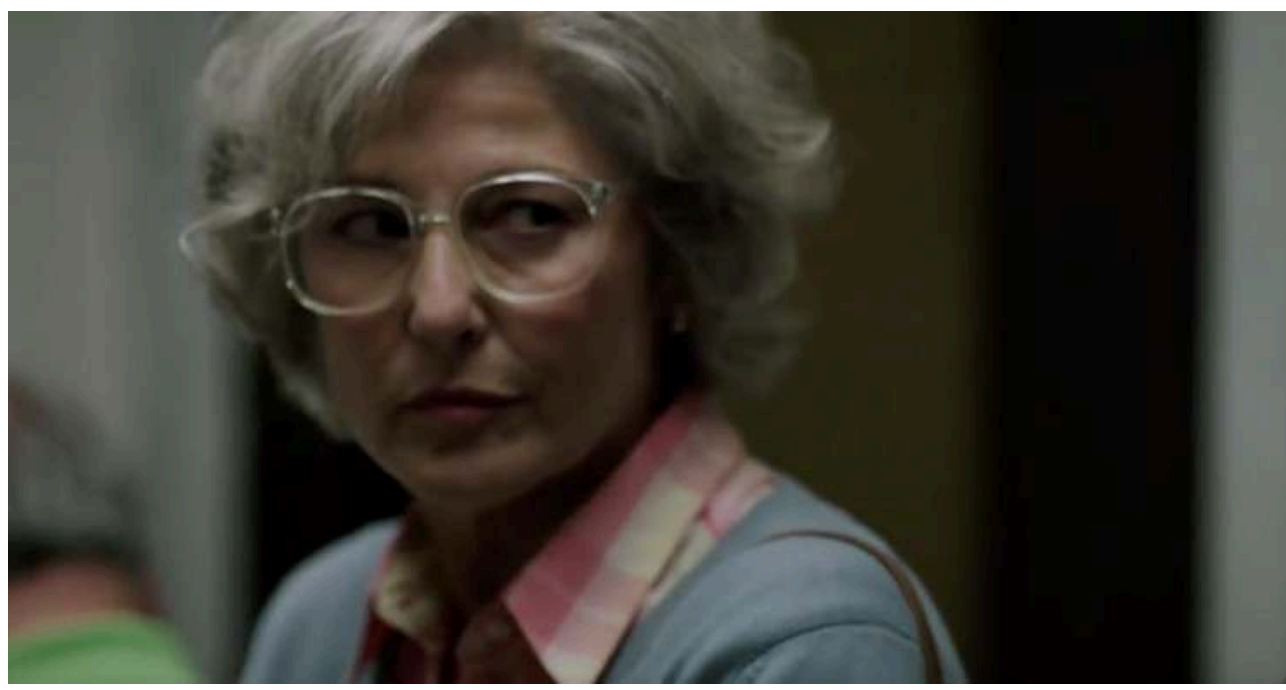

61 Or dans un premier temps elle ne dit rien, on la voit juste montrer intérieurement encore une fois, sa désapprobation, puis exprimer publiquement son point de vue dans la queue.

62 De la même manière elle refuse de sanctionner l'Église catholique quand elle donne une partie de son espace foncier pour les « housing projects» et l'exprime publiquement, sans parole mais en toute conscience. Elle est désavouée par les autres catholiques sans qu'une parole ne soit échangée. Le seul jeu des gestes, des regards, des soupirs suffit à construire la conversation. Enfin, elle marque encore son désaccord quand elle prend conscience du caractère foncièrement raciste et antisémite de la manifestation de rue à laquelle elle participe. On la voit hagarde, puis le gros plan permet de rentrer en contact avec ses sentiments.

Figures 37 et 38 : Mary dans la manifestation anti-« housing projects » (S01E04)

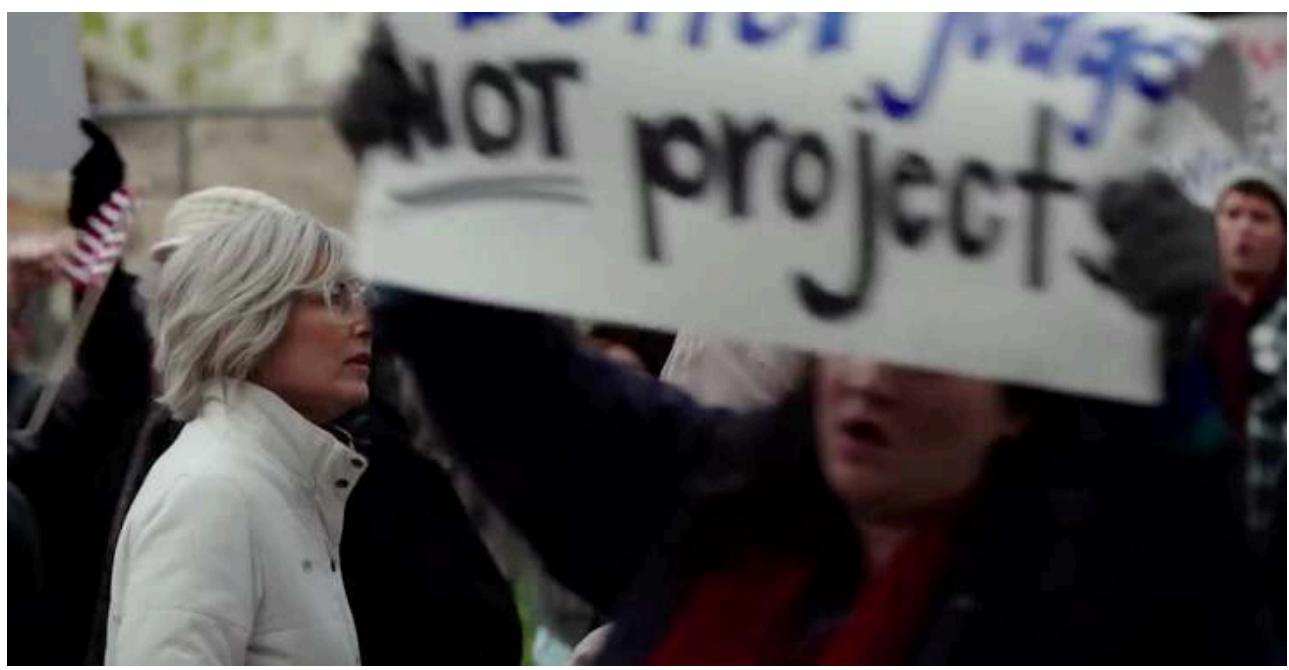




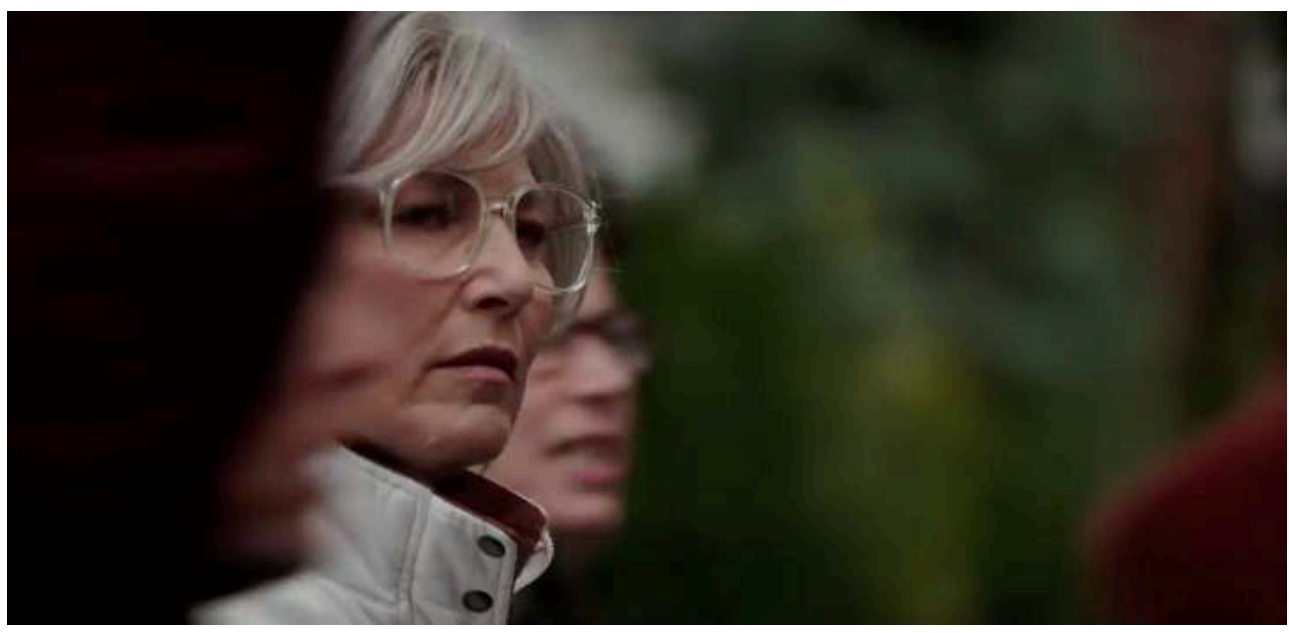
racistes blancs avec un visage exprimant une grande détermination. Mary Dorman, est une femme qui pense avec ses émotions, puis qui réfléchit, et produit une opinion conforme à ses sentiments.

Figure 39 : Mary fait face au leader du lobby blanc, elle n'est plus d'accord (S01E06)

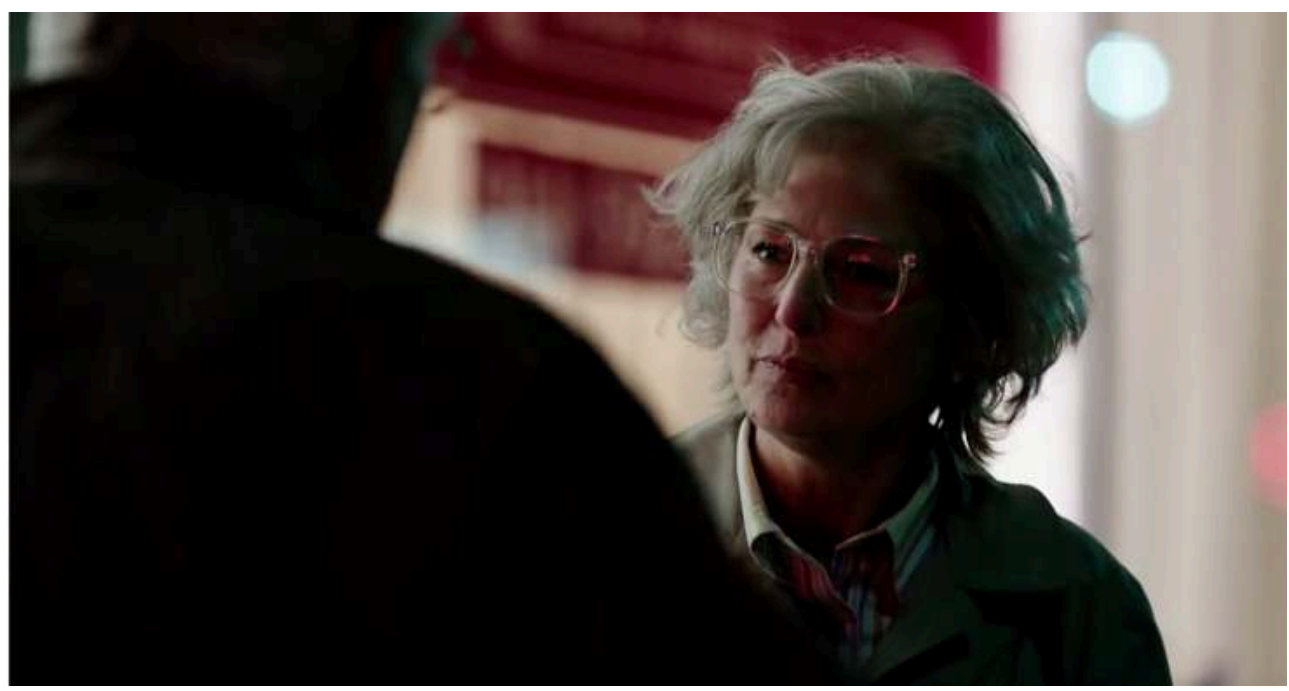

Elle est l'incarnation de la raison sensible et, même quand elle s'emporte et chevauche sans doute maladroitement ses émotions, elle revient sur l'événement et veut trouver une autre manière d'exprimer son point de vue. C'est ainsi que dans une scène improbable, du fait de l'absence de secrétariat, opportune pour le scénario, elle parle au maire pour simplement lui dire qu'elle pense avoir raison et qu'elle ne comprend pas. Son visage est alors apaisé, et on sent qu'elle essaye de réfléchir, de comprendre justement ce qui cloche dans cette affaire. Elle me fait penser alors à une cheminote gréviste qui, lors du mouvement social de l'hiver 1995, me disait « Je ne sais pas si j'ai raison de penser comme je pense, mais je n'arrête pas de penser ». Mary Dorman incarne l'énoncé de Sylvain Lazarus: «les gens pensent ». Elle incarne cette dualité sensible et le désir de savoir ce qu'elle fait et pourquoi. Le scénario nous le fait savoir, bien sûr avec ce qu'elle dit, mais la réalisation le fait surtout avec ce qu'elle montre 
d'elle dans son comportement, ses manières, ses mœurs aurait dit mon ami Saint-Just au printemps de l'an II.

Figure 40 : Mary téléphone au maire (S01E02)

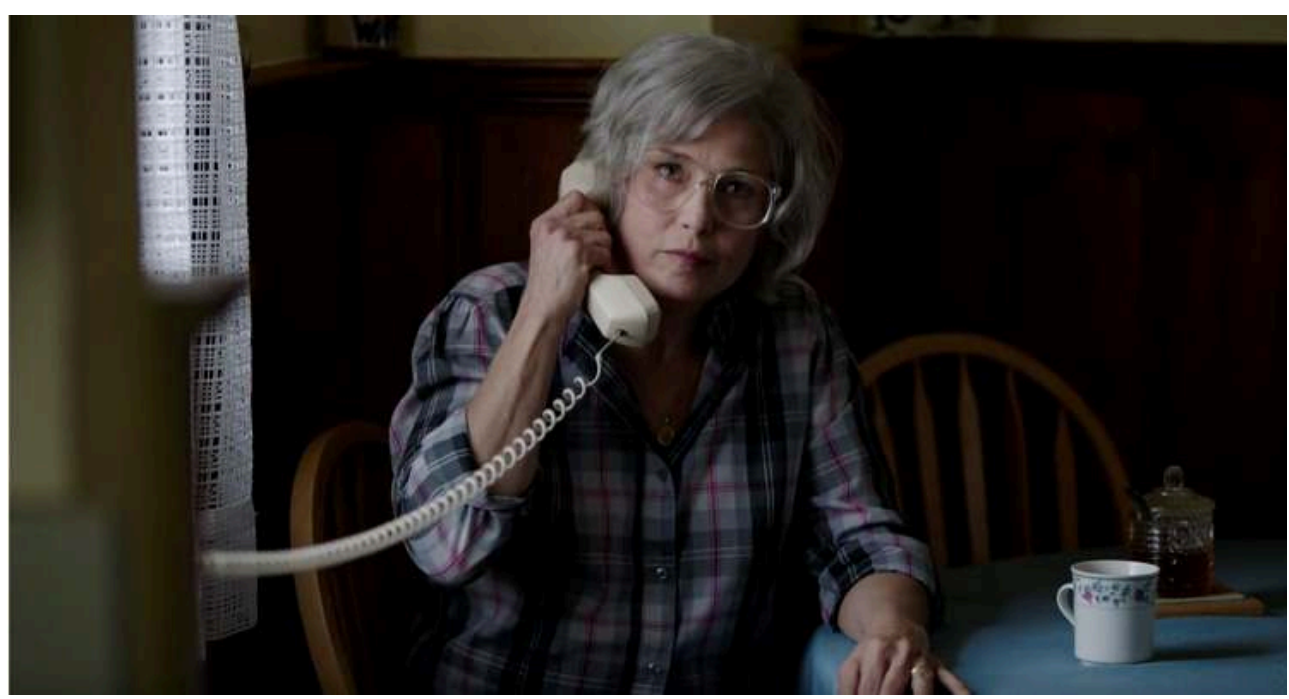

Car il ne s'agit pas simplement d'avoir pris la décision de ces « housing projects » au niveau fédéral, ni même d'obtenir le vote municipal, mais de faire entrer cette idée dans les mœurs, comme les révolutionnaires français voulaient faire entrer la Révolution dans les mœurs. Or, Mary Dorman, justement parce qu'elle a refusé très violement les "housing projects", a été choisie pour participer à l'organisation de l'accueil des nouveaux venus par les voisins. Il s'agit très classiquement aux États-Unis de faire du community organizing. Cela n'est pas classique en France aujourd'hui. Pourtant au XVIII ${ }^{\mathrm{e}}$ siècle, Saint-Just, Billaud Varenne et Robespierre y avaient réfléchi sous le nom d'institutions civiles.

\section{Community organizing/institutions civiles}

L'idée des community organizing, c'est que les relations complexes se déploient mieux quand on les accompagne. Or, faire venir des nouveaux venus noirs ou bruns dans un quartier blanc conduit à faire venir des relations complexes. Elles seront accompagnées par une figure rassurante qui parle souvent par énigmes et paraboles comme un vieux sage de temple puritain, ou comme un vieux sage africain mais en habit de manager. 
Figure 41 : Community organizer (S01E06)

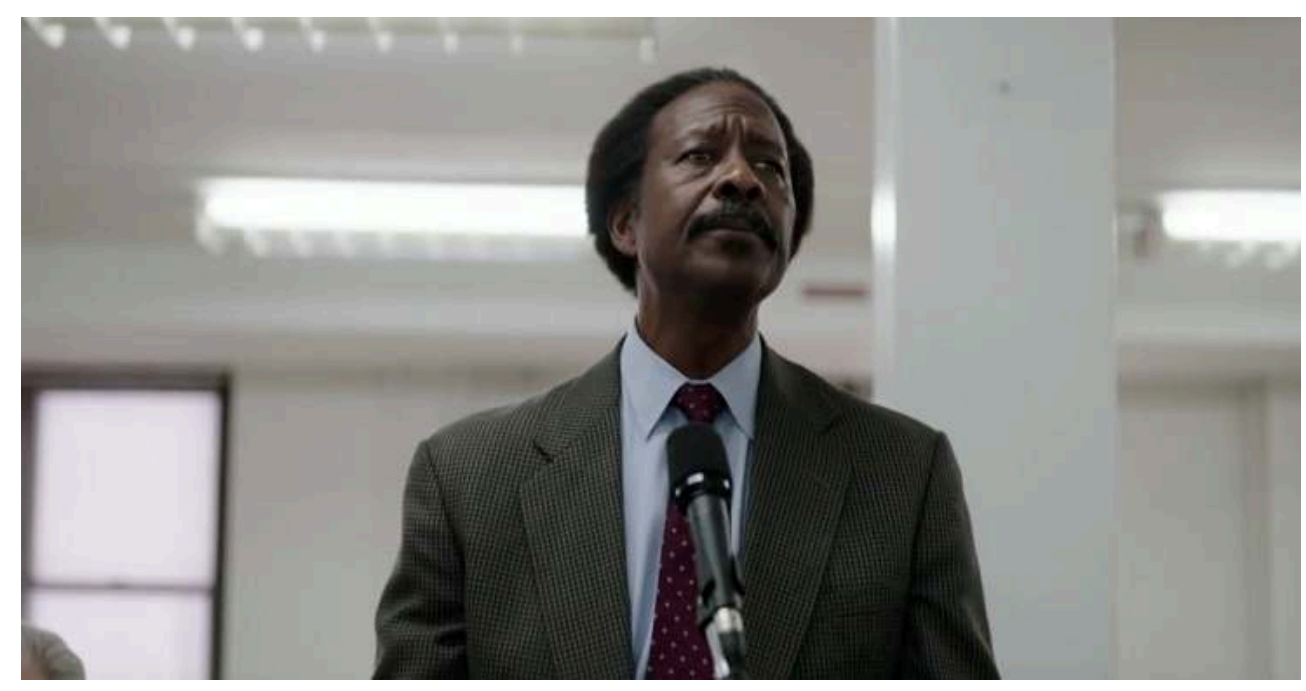

C'est un black, très intelligent, d'une intelligence sensible, intuitive plus qu'intellectuelle. « Il faut honorer l'esprit mais s'appuyer sur le cœur » disait Saint-Just.

Il rend visite à Mary Dorman et lui propose le job. Ils prennent le thé dans son intérieur modeste mais soigné. C'est une conversation qui la met en confiance, car c'est bien là le rôle de cet homme, remettre de la confiance là où les discours de Spallone, d'une part, du lobby blanc, d'autre part, ont brandi la peur de perdre toute tranquillité, toute sécurité dans le « neighbourhood».

Cette question de la confiance était aussi celle qui obsédait Saint-Just. Lorsque le 23 ventôse an II, il expliquait en quoi les factions avaient été destructrices. Il avançait que l'absence de confiance civile est le symptôme d'une société où la vie ne circule plus, d'une société brulée par la violence.

Figure 42 : le community organizer et Mary (S01E05)

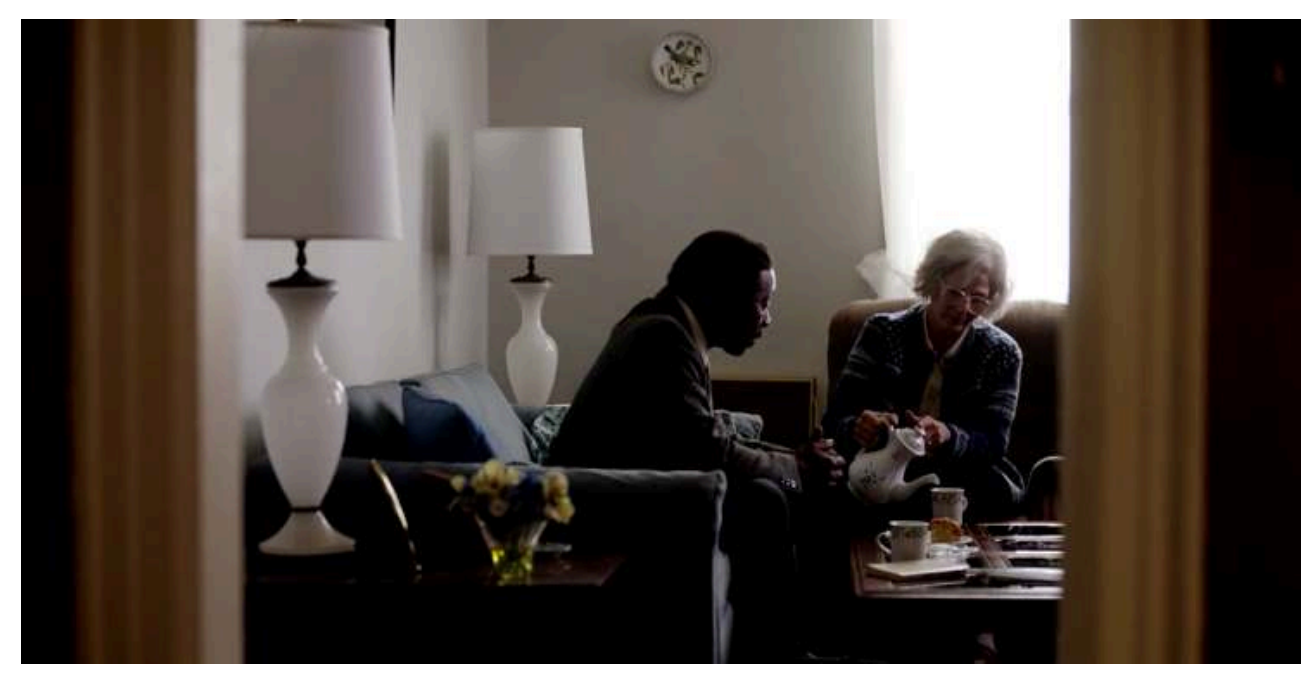

71 La destruction de la confiance civile le rend triste car ce qu'il perçoit au quotidien, c'est un manque de grandeur d'âme, une certaine petitesse, mesquinerie. Le lien social est devenu discontinu, frileux, voire redouté. En rétrécissant l'horizon de confiance et de 
joie, en sectionnant, divisant la société, on l'amène peut à peu à un niveau de fragilité qui peut conduire à l'effondrement.

72 Saint-Just dans le discours du 8 ventôse an II, évoque la question des institutions comme source de réparation et de soutien. "Un Empire se soutient-il de son propre poids, ou faut-il qu'un système profondément combiné d'institutions y mette l'harmonie ${ }^{21}$ ?»

73 La question centrale n'est peut-être pas seulement de savoir sortir de la terreur, mais d'enfin réussir à fabriquer un antidote à la division, et de permettre l'avènement de cette harmonie, de ces « mœurs ». Il conclut sa réflexion en affirmant qu'il faut « faire une cité ", faire cette harmonie, et faire c'est alors organiser les liens par des fêtes, par des activités communes comme l'écriture de poèmes et de chansons, des sociétés de théâtre, faire, c'est offrir des conditions de vie décentes aux malheureux. Nos racines communes dans l'histoire de la pensée des Lumières deviennent ici beaucoup plus lisibles.

74 Que fait le community organizer ici, il organise des réunions mixtes, tient des discours exigeants en termes de responsabilité et de " coûts » pour rassurer les Mary Dorman, et des discours rassurants pour que les membres de la communauté noire prennent aussi des responsabilités. Et le scénario nous fait retrouver Doreen...

Figures 43 et 44 : Doreen leader du community organizing (S01E06)
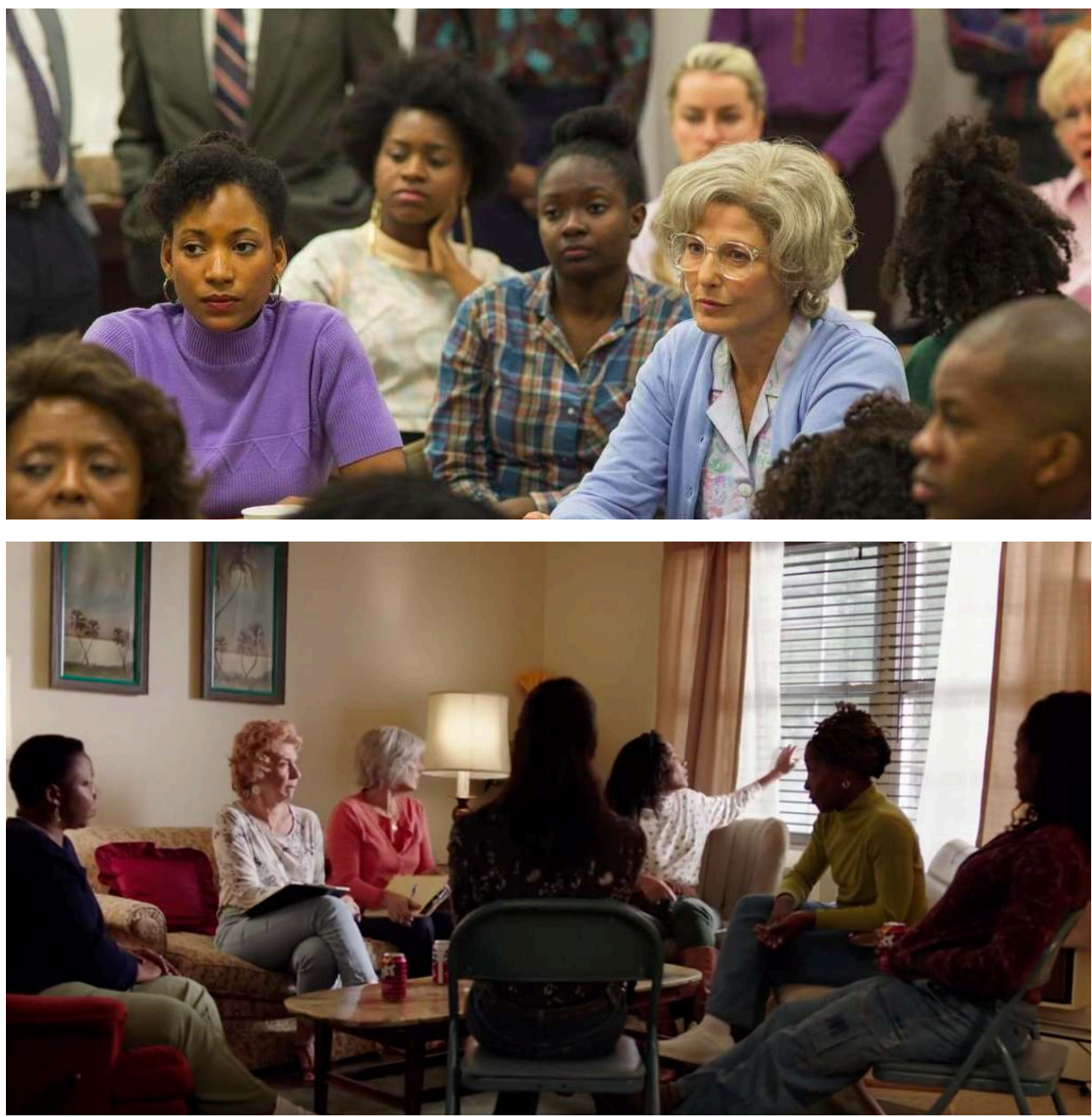

TV/Series, 19 | 2021 
75 La prise de responsabilité conjointe marque ainsi une double rédemption, ou régénération, ou réparation, aussi bien pour Doreen que pour Mary. L'une, parce qu'après avoir chevauché sa "nature privée " et l'avoir sublimée elle accède à ce « camp de la Déité » qui « assure un profit universel », c'est-à-dire à des responsabilités publiques, là où sa propre douleur l'accaparait entièrement et lui faisait prendre la fuite devant le monde. L'autre, parce qu'en écoutant sa raison sensible elle a su déjouer les sirènes de la division politique artificielle, et chevauchant sa nature publique et privée de conserve, elle trouve un nouvel art de vivre, une nouvelle forme de vie politique et sociale qui lui apporte de la joie.

\section{La politique n'apporte pas de joie : le héros tragique 22}

Il serait possible de raconter l'histoire de Nick et de Nay comme j'ai raconté l'histoire de Doreen, mais il faudrait $\mathrm{y}$ ajouter un père mort, et des amis qui trahissent, l'impossibilité pour Nick d'assumer sa position de héros ou de trop bien l'assumer tant il est conflit avec lui-même comme il se doit dans une tragédie. Il est donc lui aussi montré dans sa fragilité, avec son visage qui rit et qui pleure. Il est d'ailleurs beaucoup plus chancelant, vulnérable que Mary et Carmen, et sans doute drogué à la politique quand Doreen l'est aux stupéfiants. Or, pour Nick il n'y a pas de rédemption. La réalisation nous fait nous attacher à cet homme et à son désir quasi-enfantin de rénover une maison qui surplombe la ville, d'aimer cette jolie brune aussi modeste que lui et si bienveillante, mais il n'aime pas bricoler et n'arrive pas à l'aimer à la hauteur de ce qu'elle est elle. Il n'échappe pas au tropisme cynique de son parti. Or, ce parti produit des formes de vie qui sont loin d'être démocratiques : l'arbitraire, l'absence de sincérité, la manipulation, l'égoïsme même vis-à-vis de sa compagne, font de Nick un personnage qui habite un costume trop grand pour lui. Et, dans une certaine mesure, l'histoire se déroule presque sans lui. Lui, c'est le personnage qui permet de montrer que le care devrait peut-être commencer au sein du Parti démocrate, que l'effort perfectionniste devrait conduire à une réforme des individus comme de la structure de ce parti. L'organisme est étrange, esclavagiste au XIX ${ }^{e}$ siècle, il a joué un rôle clé dans la conquête des droits civiques dans le second $\mathrm{xx}^{\mathrm{e}}$ siècle. Il est supposé aujourd'hui lutter contre le « racial capitalism ». Mais ses élus et ses candidats sont le plus souvent des sortes d'aristocrates bien nés, riches et bien éduqués, indifférents aux soutiers de la politique que représente Nick. La lutte des classes, habite ce parti et la série montre comment. Le perfectionnisme devrait être la préoccupation de chaque acteur démocrate individuellement et collectivement, car il n'y là aucune communauté solide véritable, aucune communauté civique, certainement pas des «citoyens amis, hospitaliers et frères » en paraphrasant Saint-Just encore. Les personnages sont soit dans l'excitation et l'alcool, soit tristes et perdus. Or, les affects sociaux tels que l'amitié pourraient avoir non seulement une fonction réparatrice, mais une fonction d'exemplarité éducative sensible. Il faudrait inventer d'autres mœurs.

\section{Conclusion}

Show Me a Hero est indéniablement éligible à la liste des œuvres perfectionnistes de Cavell, nous savons désormais pourquoi, car en étant au plus près des émotions des 
acteurs nous avons partagé leurs "polarités ", le bien et le mal, l'individuel et le collectif, nous avons tout enfourché. Et effectivement comme spectateur nous en sortons sensiblement grandis. Æuuvre morale donc apte à former les citoyens, aurait dit Billaud Varenne. L'échange de secours réciproques qui lui est cher a produit dans ce quartier de Yonkers une égalisation des dignités sociales.

Cette série sans doute peut-elle rassurer la gauche américaine plus ou moins radicale qui lutte contre le « racial capitalism » en montrant qu'une femme de la lower middle class, « du monde des travailleurs» disent David Simon et Paul Haggis, entendons des non privilégiés, peut se détacher du groupe qu'elle avait spontanément trouver pour lutter contre ce qu'elle ressentait comme un danger pour sa vie quotidienne. Peut-être cette série peut-elle permettre au spectateur blanc de rencontrer la honte ${ }^{23}$ de pouvoir être assimilé à ces suprémacistes odieux, voire au Ku Klux Klan qui est encore présent plus au nord de l'État et qui inquiète la communauté noire de Yonkers. Mais elle peut permettre aussi aux démocrates affichant un supposé altruisme de savoir comment ils peuvent eux aussi se perfectionner, puisqu'ils ont laissé le héros mourir et laissé un temps venir cette nouvelle plaie dans l'expérience démocratique américaine, le « trumpisme».

J'ai vu cette série, en étant dotée des compétences d'une historienne de la Révolution française, et cela m'a aidé à écouter et entendre ce qui se jouait là. La proximité des questions révolutionnaires du printemps de l'an II et de celles de ce projet de bâtir une communauté sociale mixte me semble de première importance. Car le problème du perfectionnisme tel que traité dans les deux cas conduit à comprendre que la forme d'une société, son organisme dirait Sieyès ${ }^{24}$ plus que son organisation, ne peut pas changer avec des lois, mais suppose des liens capillaires qui viennent irriguer le corps social différemment pour faire changer ses habitudes, son habitus, le faire sortir de ses nappes de brouillard antidémocratique et réparer les brûlures de la violence de longue durée. Les brûlures de l'esclavage sont-elles (encore) réparables ? Le pessimisme est là en filigrane, mais l'optimisme domine en fait, presque trop comme s'il ne s'agissait que de savoir mieux chevaucher ses émotions contraires, chevaucher sa polarité. C'est certes aussi l'ambition de la psychanalyse, et nombre d'analystes estiment avoir vraiment réussi leur travail quand les patients commencent à vouloir s'investir dans la vie collective, la vie publique. Mais à l'heure des camisoles neuronales et du cognitivisme, art social, art politique et art de vivre sont écrasées par des puissances mortifères technocratiques, les formes de vie écrasées par l'imaginaire de la performance et de la rivalité généralisée. Aussi amoureux sommes-nous de Thoreau, d'Emerson, de Saint-Just et Billaud-Varenne, force est de reconnaître que leurs armes sont belles mais nous demandent beaucoup de patience. Or, nous sommes confrontés à l'urgence du changement. La variable temporelle laisse sur le carreau le héros, mais s'il faut trois mandatures et des morts pour engager un quartier à se perfectionner, comment la démocratie comme forme de vie peut prétendre exister avec une loi fédérale qui régresse ? Donald Trump a déstabilisé la Cour suprême en faisant élire des gens peu recommandables et se moque bien de la mixité, il a mis en équivalence à Charlotteville les agresseurs et les agressés... Les morts de Pittsburg et de San Diego ne sont pas morts en effigie mais on rencontré la dure butée du réel. La communauté noire américaine invente des formes politiques comme Black Lives Matter, mais elle est aussi épuisée. 
Bref, la série ne dit pas comment faire face à ce fossé réel, entre le lobby blanc et l'espérance mixte de la gauche démocrate américaine. Or, Mary Dorman est en fait atypique, elle est « aimable » lui dit-on.

1 Du côté français, nous avons été il y a peu avec les gilets jaunes face à un mouvement composite fait, pour une part, de Mary Dorman et fait, d'autre part, de personnes qui ne lui convenaient pas : les racistes, les antisémites. Comment éduquer ceux qui n'ont pas de point d'appuis moraux pour cette éducation, la question de la nature humaine chère à nos penseurs des Lumières, peut-elle vraiment répondre de notre devenir ?

dans cette série, la morale sociale me semble problématique, pas de rédemption montrée en dehors de la famille qui est certes la première institution civile déjà chez mes révolutionnaires, mais malgré tout pourquoi pas l'amitié sincère? Pourquoi pas des institutions plus originales, des lieux de vie pour accueillir la détresse et aider les individus à se reconstruire, comme la Maison des femmes à Paris, ou des coopératives d'habitat collaboratifs qui en font l'une de leurs fonctions? Pourquoi pas des lieux écologiques et sociaux qui sont des lieux d'hospitalité nouveaux, enfin pourquoi seulement des couples «straight »? On pourra me répondre que c'est de l'histoire, et que l'archive a ses droits. Mais c'est bien là une véritable question esthétique et politique, si l'histoire peut servir à parler du présent, dans quelles limites ? Comment esthétiquement relier le passé proche, Yonkers années 1980, le passé plus lointain dans son épaisseur, de l'esclavage aux droits civiques, au présent?

Il faudra sans doute inventer encore des formes à enfourcher.

J'avais un cheval dans un champ de ciel Et je m'avançais dans le jour ardent... Jules Supervielle.

\section{BIBLIOGRAPHIE}

BOURDIEU, Pierre Le sens pratique, Paris, Minuit, coll. « Le sens commun », 1980.

CAVELL, Stanley, Conditions Handsome and Unhandsome. The Constitution of Emersonian Perfectionism.

The Carus Lectures, 1988, Chicago, University of Chicago Press, 1990.

CAVELL, Stanley, Conditions nobles et ignobles. La constitution du perfectionnisme émersonien [ $1^{\mathrm{e}}$ éd. :

1990], trad. franç. par Christian FOURNIER et Sandra LAUGIER, in Qu'est-ce que la philosophie

américaine? De Wittgenstein à Emerson, Paris, Gallimard, coll. « Folio Essais », 2009, p. 153-414.

CAVELL, Stanley, Statuts d'Emerson. Constitution, philosophie, politique [1 $1^{\mathrm{e}}$ éd. : 1992], trad. franç. par Sandra LAUGIER, in Qu'est-ce que la philosophie américaine? De Wittgenstein à Emerson, ibid., p. 435-474. DEWEY, John, Le public et ses problèmes [1 éd. : 1927], Paris, Gallimard, coll. « Folio essais », 2010. DIDIER-WEILL, Alain, Les trois temps de la loi. Le commandement sidérant, l'injonction du surmoi et l'invocation musicale [1éd. : 1995], Paris, Seuil, coll. « La couleur des idées », 2008. 
DREIER, Peter, ATLAS, John, « The Wire: Bush-Era Fable about America's Urban Poor? », City \& Community, vol. 8, issue 3, September 1, 2009, pp. 329-340.

EMERSON, Ralph Waldo, Fate [conférence de 1851, publiée dans The Conduct of Life en 1860], https:// emersoncentral.com/texts/the-conduct-of-life/fate/ ; trad. franç. par Christian FOURNIER, sous le titre « Destin », in Stanley CAVELL, Qu'est-ce que la philosophie américaine ? De Wittgenstein à Emerson, op. cit., p. 476-503.

Guilhaumou, Jacques, "Sieyès et le non-dit de la sociologie : du mot à la chose ", Revue d'Histoire des Sciences Humaines, $\mathrm{n}^{\circ}$ 15, novembre 2006, p. 117-134, https://www.cairn.info/revue-histoiredes-sciences-humaines-2006-2-page-117.htm.

LAPIERRE, Nicole, Causes communes. Des juifs et des noirs, Paris, Stock, coll. « Un ordre d'idées », 2011. LAUGIER, Sandra, «Les séries télévisées : éthique du care et adresse au public », Raison publique, $\mathrm{n}^{\circ}$ 11, octobre 2009, p. 277-288, repris sur https://www.academia.edu/37113701/

Les_s\%C3\%A9ries_t\%C3\%A91\%C3\%A9vis\%C3\%A9es_\%C3\%A9thique_du_care_et_adresse_au_public. LAUGIER, Sandra, éd., La voix et la vertu. Variétés du perfectionnisme moral, Paris, PUF, coll. « Éthique et philosophie morale ", 2010.

LEVINAS, Emmanuel, Totalité et Infini. Essai sur l'extériorité [1éd. : 1961], Paris, Le Livre de poche, 1990.

LORAUX, Nicole, «Eloge de l'anachronisme en histoire », Le genre humain, n² 27, 1993, p. 23-39, https://www.cairn.info/revue-le-genre-humain-1993-1-page-23.htm.

LORAUX, Patrice, « Les disparus », Le Genre humain, n 36, 2001, p. 41-57, https://www.cairn.info/ revue-le-genre-humain-2001-1-page-41.htm.

MAZA, Sarah, Vie privées, affaire publiques. Les causes célèbres de la France prérévolutionnaire, Paris, Fayard, 1997.

MORGENTHALER, Jean-Louis, « Condorcet, Sieyès, Saint-Simon et Comte. Retour sur une anamorphose », Socio-logos, n 2, 2007, http://journals.openedition.org/socio-logos/373.

SAINT-JUST, Euvres complètes, précédés par « Lire Saint-Just » par Miguel ABENSOUR, édition établie et présentée par Anne KUPIEC et Miguel ABENSOUR, Paris, Gallimard, coll. « Folio Histoire », 2004.

SARTRE, Jean-Paul, Critique de la raison dialectique [1 ${ }^{\mathrm{e}}$ éd. : 1960], Paris, Gallimard, coll. « Bibliothèque de Philosophie », 2 tomes, 1985.

TAї̈B, Emmanuel, « The Wire : séries et sciences sociales », Revue française de science politique, août 2017, vol. 67, n 4, p. 731-736, repris sur http://emmanueltaieb.fr/wp-content/uploads/2014/06/ Taieb-RFSP-67-4-2017.pdf.

WAHNICH, Sophie, La longue patience du peuple, 1792. Naissance de la République, Paris, Payot, coll. «Critique de la politique », 2008.

WAHNICH, Sophie, «Show Me a Hero : Vengeance des lois et violence mythique ", Débordements, $\mathrm{n}^{\circ} 1$, avril 2019, p. 160-178.

\section{NOTES}

1. Voir Peter Dreier and John Atlas, "The Wire: Bush-Era Fable about America's Urban Poor?", City \& Community, vol. 8, issue 3, September 1, 2009, pp. 329-340. 
2. Le terme est ici sciemment et évidemment employé en référence à la philosophie de Stanley Cavell lecteur d'Emerson: voir Stanley Cavell, Conditions Handsome and Unhandsome. The Constitution of Emersonian Perfectionism. The Carus Lectures, 1988, Chicago, University of Chicago Press, 1990, et La voix et la vertu. Variétés du perfectionnisme moral, éd. Sandra Laugier, Paris, PUF, coll. « Éthique et philosophie morale », 2010.

3. L'émission CBS This morning sur la série du 12 août 2015, animée par Charlie Rose, permet de mesurer les intentions explicites de David Simon et Paul Haggis : «David Simon on "Show Me a Hero" ", YouTube, 13 août 2015, www.youtube.com/watch?v=uQZedy2td9U.

4. Nicole Loraux, «Eloge de l'anachronisme en histoire », Le genre humain, n 27, 1993, p. 23-39, https://www.cairn.info/revue-le-genre-humain-1993-1-page-23.htm.

5. Pierre Bourdieu, Le sens pratique, Paris, Minuit, 1980, p. 94.

6. Sur cette question, voir Nicole Lapierre, Causes communes. Des juifs et des noirs, Paris, Stock, coll. «Un ordre d'idées », 2011.

7. Voir Jean-Paul Sartre, Critique de la raison dialectique [1 ${ }^{\mathrm{e}}$ éd.: 1960], Paris, Gallimard, coll. «Bibliothèque de Philosophie », 2 tomes, 1985.

8. Voir Ralph Waldo Emerson, Fate [conférence de 1851, publié dans The Conduct of Life en 1860], https://emersoncentral.com/texts/the-conduct-of-life/fate/, Stanley Cavell, Statuts d'Emerson. Constitution, philosophie, politique [1 ${ }^{\mathrm{e}}$ éd.: 1992], in Qu'est-ce que la philosophie américaine? De Wittgenstein à Emerson, Paris, Gallimard, coll. «Folio Essais », 2009, p. 435-474, et La voix et la vertu. Variétés du perfectionnisme moral, éd. Sandra Laugier, op. cit.

9. Sur cette notion, voir Sophie Wahnich, La longue patience du peuple, 1792. Naissance de la République, Paris, Payot, coll. «Critique de la politique », 2008.

10. Ralph Waldo Emerson, «Destin » [«Fate », conférence de 1851, publiée en 1860], in Cavell, Qu'est-ce que la philosophie américaine? De Wittgenstein à Emerson, op.cit., p. 476.

11. Voir Emmanuel Levinas, Totalité et Infini. Essai sur l'extériorité [1éd. : 1961], Paris, Le Livre de poche, 1990.

12. Ibid., p. 61.

13. Emerson, « Destin », op. cit., p. 502.

14. Stanley Cavell, Conditions nobles et ignobles. La constitution du perfectionnisme émersonien [ $1^{\mathrm{e}}$ éd. : 1990], in Qu'est-ce que la philosophie américaine ?, op.cit. p. 235.

15. Voir John Dewey, Le public et ses problèmes [1 éd. : 1927], Paris, Gallimard, coll. « Folio essais », 2010, mais aussi en écho rétroactif prospectif Sarah Maza, Vie privées, affaire publiques. Les causes célèbres de la France prérévolutionnaire, Paris, Fayard, 1997.

16. L'expression vient des esclavagistes du XVIII ${ }^{\mathrm{e}}$ siècle qui théorisent leur devoir être, ne rien ressentir face à la douleur des esclaves.

17. Sandra Laugier, «Les séries télévisées : éthique du care et adresse au public », Raison publique, $\mathrm{n}^{\circ} 11$, octobre 2009, p. 277-288, repris sur https://www.academia.edu/37113701/ Les_s\%C3\%A9ries_t\%C3\%A91\%C3\%A9vis\%C3\%A9es_\%C3\%A9thique_du_care_et_adresse_au_public. 18. J'emprunte cette remarque à Alain Didier-Weill, Les trois temps de la loi. Le commandement sidérant, l'injonction du surmoi et l'invocation musicale [1 éd. : 1995], Paris, Seuil, coll. « La couleur des idées », 2008.

19. Pour Cavell, «le perfectionnisme est la dimension de le pensée morale qui vise moins à réfréner le mal qu'à libérer le bien ", Conditions nobles et ignobles. La constitution du perfectionnisme émersonien, op. cit., p.235.

20. Emmanuel Taïeb, «The Wire : séries et sciences sociales", Revue française de science politique, août 2017, vol. 67, $\mathrm{n}^{\circ}$ 4, p. 734, repris sur http://emmanueltaieb.fr/wp-content/uploads/2014/06/ Taieb-RFSP-67-4-2017.pdf.

21. Saint-Just, Cuvres complètes, édition établie et présentée par Anne Kupiec et Miguel Abensour, Paris, Gallimard, coll. « Folio Histoire », 2004, p. 657. 
22. J'ai développé cette question spécifique du héros tragique dans son rapport à la loi dans «Show Me a Hero: Vengeance des lois et violence mythique », Débordements, n 1, avril 2019, p. 160-178.

23. Chez Levinas, la honte surgit dans le conflit entre un désir irrépressible de se fuir et l'impossibilité de toute évasion, quand on ne peut plus cacher ce que nous voulions soustraire au regard. Avoir honte c'est ainsi être livré à l'inassumable et par là même en prendre conscience. La honte permettrait de ne plus rester impassible, elle serait le retour conflictuel d'un affect après la pétrification de l'affectivité. Sur cette question de l'impassibilité, de l'effraction et de la honte, on pourra lire Patrice Loraux, «Les disparus ", Le Genre humain, n³6, 2001, p. 41-57, https://www.cairn.info/revue-le-genre-humain-2001-1-page-41.htm.

24. Voir Jacques Guilhaumou, "Sieyès et le non-dit de la sociologie : du mot à la chose ", Revue d'Histoire des Sciences Humaines, $\mathrm{n}^{\circ}$ 15, novembre 2006, p. 117-134, https://www.cairn.info/revuehistoire-des-sciences-humaines-2006-2-page-117.htm, et Jean-Louis Morgenthaler, «Condorcet, Sieyès, Saint-Simon et Comte. Retour sur une anamorphose ", Socio-logos, n 2, 2007, http:// journals.openedition.org/socio-logos/373.

\section{RÉSUMÉS}

La mini-série Show Me a Hero, est un produit HBO crée par David Simon et réalisée par Paul Haggis. La ségrégation y est mise en scène à Yonkers, ville du nord de l'Etat de New York, voisine de New York City. Le regard porté sur le voisinage se fait sur plusieurs échelles spatiales et plusieurs représentations temporelles entre un passé proche, celui des années 1980 qui sont celles de l'intrigue, notre présent qui motive la réalisation de cette mini-série, les traces d'un passé tragique plus lointain.

L'article explicite pourquoi cette mini-série peut faire partie de la liste que Stanley Cavell donnait à ses étudiants pour définir le perfectionnisme sans donner de définition. Sont ainsi examinés les politiques publiques de déségrégation comme processus du perfectionnisme collectif, mais aussi les trajectoires de rédemption de personnages qui soit refusent les housing projects soit en ont cruellement besoin. La question des visages et des émotions qui traversent les sujets pensants est à cet égard déterminante pour comprendre comment le jugement réflexif est aussi un jugement par les émotions qui font basculer les trajectoires individuelles. Des victimes peuvent se ressaisir de leur vie, se politiser, ou simplement se " perfectionner ", des personnages terrifiants peuvent aussi devenir aimables. Il s'agit de comprendre la compétence perfectionniste d'une communauté d'habitants.

The miniseries Show Me a Hero, is an HBO product created by David Simon and directed by Paul Haggis. We witness segregation in Yonkers, a northern city in the state of New York, next to New York City. The representation of the neighbourhood is made on several spatial scales and several temporal representations, between a recent past, that of the 1980 s when the plot takes place, our present that motivates the production of this miniseries, and the traces of a more remote, tragic past.

This article explains why this miniseries can be part of the list that Stanley Cavell gave his students to define perfectionism without giving a definition. Public policies of desegregation as a process of collective perfectionism are thus examined, but also the trajectories of redemption of characters who either oppose the housing projects, or badly need them. It is essential to study 
how faces and emotions affecting the thinking subjects show how reflexive judgment is also a judgment by emotions that tip individual trajectories. Victims can take hold of their lives again, become involved in politics, or simply "improve". Terrifying characters can also become likeable. The point is to understand the perfectionist competence of a community of citizens.

\section{INDEX}

Mots-clés : communauté, émotion, perfectionnisme, ségrégation, voisinage

Keywords : community, emotion, neighbourhood, perfectionism, segregation

\section{AUTEUR}

\section{SOPHIE WAHNICH}

Sophie Wahnich est directrice de recherche au CNRS, agrégée et docteure en histoire, elle dirige des recherches en science politique. Après avoir enseigné à Dijon et Aix-en-Provence elle a soutenu une thèse sur la notion d'étranger pendant la révolution française. Elle est alors entrée au CNRS en 1995 en science politique (section 40) et a travaillé sur les émotions politiques. Elle œuvre pour réactiver le laboratoire révolutionnaire pour le présent. Elle est notamment l'auteure de : L'impossible citoyen. L'étranger dans le discours de la Révolution française (Albin Michel, 1997, rééd. en 2010), Les émotions, la Révolution française et le présent (Éditions du CNRS, 2009), In Defence of Terror: Liberty or Death in the French Révolution (Verso, 2012, traduction de La liberté ou la mort. Essai sur la Terreur et le terrorisme, La Fabrique 2003) et La Révolution française n'est pas un mythe (Klincksieck, coll. «Critique de la politique », 2017).

Sophie Wahnich is a senior researcher in political science at the CNRS, she holds the "agregation" in history, a PhD in history and supervises research in history and political science. After teaching at the University of Aix-en-Provence and then Dijon, she supported a PhD on the notion of foreigner in the age of the French Revolution. She joined the CNRS in 1995 in the political science section (40). She then focused her research on the emotional part of political practices, moving away from the analyses that make the most of the rationality of the actors. She works to reactivate the laboratory of the French Revolution in a report to the present. She is the author of, among others: L'impossible citoyen. L'étranger dans le discours de la Révolution française (Albin Michel, 1997, reed. in 2010), Les émotions, la Révolution française et le présent (Éditions du CNRS, 2009), In Defence of Terror: Liberty or Death in the French Révolution (Verso, 2012) et La Révolution française n'est pas un mythe (Klincksieck, coll. “Critique de la politique”, 2017). 